This PDF is a selection from a published volume from the National Bureau of Economic Research

Volume Title: Measuring and Modeling Health Care Costs

Volume Author/Editor: Ana Aizcorbe, Colin Baker, Ernst R. Berndt, and David M. Cutler, editors

Volume Publisher: University of Chicago Press

Volume ISBNs: 978-0-226-53085-7 (cloth); 978-0-226-53099-4 (e-ISBN)

Volume URL: http://www.nber.org/books/aizc13-1

Conference Date: October 18-19, 2013

Publication Date: February 2018

Chapter Title: Specialty Drug Prices and Utilization after Loss of U.S.

Patent Exclusivity, 2001-2007

Chapter Author(s): Rena M. Conti, Ernst R. Berndt

Chapter URL: http://www.nber.org/chapters/c13100

Chapter pages in book: (p. $273-321)$ 


\title{
Specialty Drug Prices and Utilization after Loss of US Patent Exclusivity, 2001-2007
}

\author{
Rena M. Conti and Ernst R. Berndt
}

\subsection{Introduction}

We examine the impact of generic entry on the prices and utilization of prescription drugs between 2001 and 2007 in the United States (US). Whereas previous research on the impact of loss of exclusivity (LOE) on entry patterns and use trends following the enactment of the 1984 Drug Price Competition and Patent Term Restoration Act (the "Hatch-Waxman Act") has focused primarily on self-administered oral and tablet/capsule formulations dispensed through the retail pharmacy sector, here we focus on specialty drugs. Although there is no universally accepted definition of specialty drugs, typically they fall into at least one of several categories: they are physician-administered parenterally or self-administered by patients

Rena M. Conti is associate professor of pediatrics and public health sciences at the University of Chicago. Ernst R. Berndt is the Louis E. Seley Professor in Applied Economics at the MIT Sloan School of Management and a research associate of the National Bureau of Economic Research.

The efforts of Conti were funded by a K07 CA138906 award from the National Cancer Institute to the University of Chicago. Berndt's efforts were not sponsored. The funding source had no role in the design and conduct of the study; collection, management, analysis, or interpretation of the data; and preparation, review, or approval of the manuscript for publication. The statements, findings, conclusions, views, and opinions contained and expressed in this chapter are those of the authors and are based in part on National Sales Perspectives data obtained by the National Bureau of Economic Research (NBER) under license from IMS Health (all rights reserved), and are not necessarily those of IMS Health, its affiliates or subsidiaries, or the institutions with whom the authors are affiliated. We thank David Cutler, Judy Hellerstein, Christopher Stromberg, and participants at the October 18-19, 2013, NBER/Conference on Research in Income and Wealth, "Measuring and Modeling Health Care Costs" in Washington, DC, for helpful comments. All errors are our own. For acknowledgments, sources of research support, and disclosure of the authors' material financial relationships, if any, please see http:// www.nber.org/chapters/c13100.ack. 
through injection, inhalation, or another nonoral method; they require specialized knowledge or manufacturing processes to reliably and reproducibly manufacture; they entail specialty distribution channels rather than retail pharmacies; they are covered under the outpatient medical benefit of public and private insurers; and when patent protected are said to have "high prices." Among those categories, here we limit our empirical cohort to specialty drugs commonly used to treat cancer, and base our analyses on nationally representative data from IMS Health on monthly volume and inflation-adjusted sales revenues. This empirical focus is relevant both to researchers and policymakers. While the market for producing cancer drugs is small compared to that of all prescription drug manufacturing, specialty drug use is an important driver of current national prescription drug spending levels and trends (Aitken, Berndt, and Cutler 2009; GAO 2013). The potential impact on national spending levels and trends among high-price and high-revenue cancer and other specialty drugs expected to undergo LOE is the subject of significant policy interest (US Department of Health and Human Services [OIG] 2011; Conti et al. 2013).

Among pharmaceuticals, LOE opens a drug up to potential competition from multiple manufacturers previously limited to the sole "branded" producer. Price and utilization of drugs post-LOE have been studied extensively among nonspecialty drugs (Caves, Whinston, and Hurwitz 1991; Grabowski and Vernon 1992, 1996; Frank and Salkever 1997; Wiggins and Maness 2004; Reiffen and Ward 2005; Berndt, Kyle, and Ling 2003). Our chapter contributes to this literature by describing the average number of manufacturers entering specialty drugs undergoing LOE in the first year after patent expiration and thereafter, and by comparing raw counts of generic firm entrants to those observed among studies of specialty and nonspecialty drugs in a contemporaneous cohort (Scott Morton 1999, 2000). However, we do not derive welfare implications from these entry count results. Our review of the organization of specialty drug-production literature suggests the substantial presence of time-varying and unobservable contract manufacturing practices seriously complicates and may even obviate the definition of unique "manufacturers" entering this market.

Rather, using pooled cross-sectional and time-series methods, we engage in a three-step examination of whether the neoclassical relationship between presumed price declines upon LOE and volume increases holds among these drugs. First, we examine the extent to which estimated prices of these drugs undergoing LOE fall with generic entry among oral and physician-administered (injected and/or infused) drug formulations. Second, we document raw trends in inflation-adjusted sales revenues and utilization following initial LOE. Third, we estimate reduced-form random effect models of utilization subsequent to LOE, accounting for molecule formulation and therapeutic class and entry patterns (Wiggins and Maness 2004). We discuss second-best welfare consequences of these estimated 
prices and use results after acknowledging the presence of complications to first-best welfare calculations in this market. Finally, we examine whether molecule characteristics and utilization patterns can help predict drug shortages that occurred in the United States subsequent to our 2001-2007 sample time period.

\subsection{Unique Institutions Governing Generic Entry, Manufacturing, and Pricing of Specialty Drugs}

In this section, we review unique aspects of the supply and demand for specialty drugs. This discussion is not meant to be exhaustive, but rather is intended to provide sufficient context to motivate our empirical approach and lay the foundation for the interpretation and discussion of our findings.

\subsubsection{Branded and Generic Drug Regulatory Approval}

The prescription drug market distinguishes two types of drugs. Brand name ("innovator") drugs are approved for use in a given indication by the US Food and Drug Administration (FDA) under New Drug Applications (NDAs) submitted by pioneer manufacturers typically based on the results of one or two phase III randomized controlled clinical trials. Pioneer manufacturers are able to sell their products exclusively while the drug is patent protected. In anticipation of patent expiration and any other loss of exclusivity, other manufacturers (called "sponsors") apply to the FDA to obtain approval to market the "generic" drug under an Abbreviated New Drug Application (ANDA).

The FDA approval of an ANDA does not require its sponsor to repeat clinical or animal research on active ingredients or finished dosage forms already found to be safe and effective. Rather, to gain approval the ANDA sponsor must only establish that the generic contains the same active ingredients; be identical in strength, dosage form, and route of administration; be bioequivalent; and be manufactured under the same strict standards as the brand-name drug. When submitting an ANDA, a sponsor provides evidence either substantiating bioequivalence and compliance with current good manufacturing practices (CGMP) at its own manufacturing sites, or else indicates that portions of the manufacturing (such as production of active pharmaceutical ingredients [APIs] or final fill and finish production) will be outsourced to another supplier or contract manufacturing organization [CMO]). The FDA is responsible for enforcing ANDA requirements and CGMP standards among generic manufacturers both upon entry and via subsequent periodic routine inspections. Production facilities may be inspected and certified postapproval to verify they meet FDA requirements, including in particular specific lines, vats, and batches; typically inspections occur every eighteen to thirty-six months per facility. For oral tablets and capsules, the direct costs of ANDA applications are modest ( $\$ 1-\$ 5$ million) 
compared to potential profitability (Berndt and Newhouse 2013). Not much is known regarding the direct costs of obtaining ANDA approvals among infused or injected drugs.

\subsubsection{Supply Conditions}

What is known is that the manufacturing technology involved in the production of infused or injected drugs is highly specialized. Sterility is particularly important for these drugs, providing the primary challenge related to their manufacturing, packaging, and distribution. Sterile production requires keeping human operator intervention to a minimum, which is accomplished by separating or removing highly trained and skilled employees from the aseptic clean air and water environment. Contamination can involve pathogens, fragments of vial rubber stoppers, and broken glass. Because manual steps create opportunities for contamination, automated processes for the filling and finishing of these products are desirable. Unlike most capsules and tablets, liquid active pharmaceutical ingredients (API) are the base materials for production of these drugs. Risk of contamination is also important in the sourcing of API. The API is typically sterilized using filtration, with the sterile product then held in an aseptic storage tank until it is used for final "fill and finish" ANDA production.

Therefore, even though regulatory barriers to entry among manufacturers of these drugs are likely rather modest, the small market size and high fixed and variable production costs of at least some specialty drugs likely results in modest entry post-LOE and production being concentrated among specialized manufacturers. Evidence in support of this market characterization is derived from multiple sources. From industry sources, it is clear manufacturers with noted current commitments to the production of specialized injected or infused drugs for the domestic market include Hospira, Teva Pharmaceuticals and Teva Parenteral ME, and Baxter and Fresenius (APP) (EMD Serono 2013; PBMI 2014). Furthermore, only a handful of injected or infused generic drug manufacturers produce their own liquid or lyophilized API (Teva, Sandoz, and Watson), with the remaining manufacturers acquiring it from nonaffiliated producers. Adding some measure of confidence to our characterization, we note these observations are consistent with previous empirical work on generic entry into these markets, suggesting the mean number of approved ANDA sponsors of injected or infused specialty drugs ranges between two and five, compared to the five to fifteen ANDA sponsors of oral drugs undergoing LOE between 1984 and 1994 in the United States (Scott Morton 1999, 2000; Aitken et al. 2013) and among oral drugs undergoing LOE in Japan between 2004 and 2006 (Iizuka 2009).

Another important characteristic of the market for injected or infused drugs is that a number of prominent manufacturers hold ANDAs for their own drugs and simultaneously act as contract manufacturers for others (e.g., Hospira, Boehringer Ingelheim, Luitpold, Fresenius/APP, West-Ward) 
(FDA 2011; Conti 2014). For example, one notable manufacturer of many generic injectable drugs, Ben Venue, was (until very recently) the CMO subsidiary of Boehringer Ingelheim of Germany. There are likely significant cost efficiencies gained from outsourcing the production of injected or infused drugs to established CMOs. To the extent that they are able to exploit economies of scope and scale, CMOs can offer their services at a cost lower than that incurred by self-manufacturing. Moreover, because of scope economies, CMOs face incentives to expand the portfolio of products they produce, but they can also take advantage of scale economies, producing the same injected or infused drug for different ANDA sponsors (Macher and Nickerson 2006). A recent report (FDA 2011) documents more than a doubling of manufacturers relying on CMOs among branded and generic drugs worldwide between 2001 and 2010.

Yet, the FDA does not make public a list of which CMOs manufacture a given drug. As far as we are aware, this information is not made available publicly by any other regulatory agency or private data vendor, either. Thus, the importance of contract manufacturing for drugs supplied to the US market generally (both specialty and nonspecialty), and our sample of drugs specifically, is unobservable by researchers, stakeholders, and regulators. This point fundamentally casts doubt on the validity of simple manufacturer counts, as well as on the interpretation of manufacturing count entry models of any and all generic drugs, and has further implications for policymakers charged with monitoring competition in this market.

\subsubsection{Information and Regulatory Timing}

The FDA does not publicly reveal when it receives an ANDA, nor the identity of its sponsor. In this sense, the limited information regarding the entry process is symmetric and simultaneous among potential entrants. However, sponsor executives might announce their entry plans to inform their shareholders. Scott Morton (1999) suggests such announcements may be used to deter other competitors from entering the market. Although a firm may announce its intentions to enter the supply of a particular molecule for the domestic market, there is no guarantee that FDA approval will be granted in the time frame anticipated by the applicant. Consequently, an ANDA sponsor cannot generally credibly commit to a market with its application announcement alone.

Supporting this view, a review of recent trends suggests the timing of ANDA approval has become more variable for sponsors between 2001 and 2011 and consequently less predictable among potential entrants (Parexel 2013). While the number of original total ANDA approvals has increased substantially, from 132 in 2001 and 392 in 2007 to 422 in 2011, the number of original injectable ANDA approvals also increased from thirty-two in 2001 (24.2 percent of total) and sixty-four in 2007 (16.3 percent of total) to eighty-eight in 2011 (21 percent of total). Mean (median) FDA ANDA 
review times initially fell from 21.1 (18.1) months in 2001 to 19.9 (15.7) months in 2004, but then increased to 21.4 (18.9) months in 2007 and 32.9 (29.5) months in 2011. The number of backlogged pending ANDAs under FDA review increased sharply during this period, from 374 in 2001 to 615 in 2004, 1,309 in 2007, and 2,693 in 2011.

\subsubsection{Drug Shortages}

Since 2006, the United States has experienced a marked increase in prescription drug shortages. Three-quarters of shorted drugs in 2011 were sterile injectable products, such as chemotherapy, anesthesia, and antiinfective agents (US Department of Health and Human Services [ASPE] 2011; Woodcock and Wosinska 2013) and over 80 percent had lost patent protection, experienced generic entry, and consequently were (in theory) multisourced by competing generic drug manufacturers. The majority of generic specialty-drug shortages initially appeared around 2009 and thereafter. These shortages have raised specific alarm since the welfare consequences for pediatric cancers and discontinuation of clinical trials are presumed to be disproportionately high (Gatesman and Smith 2011; Wilson 2012). The University of Utah Drug Information Service tracks the number of shortages at the end of each quarter. Recently, they reported that over the past five quarters the number of shortages was at the highest level since the beginning of 2010. This growth is primarily due to the unusual persistence of existing shortages rather than growth in the number of new shortages (Goldberg 2013).

The proximal causes of most domestic drug shortages are also clear. Beginning around 2009-2011, routine certification inspections performed by the FDA uncovered significant lapses in maintenance of facilities that produce the fill and finished dosage of the drug among many manufacturers (Woodcock and Wosinska 2013). Various inspections investigating suspected lapses in manufacturing practices resulted in the closure of other "fill and finish" facilities (Ben Venue and American Regent in 2010 and Ranbaxy in 2014) and API suppliers (Ranbaxy in 2014). Perhaps as a consequence, policy efforts to mitigate shortages have largely focused on improving the FDA's capabilities to respond to the crises (FDA 2013).

\subsubsection{Supply and Demand Side Prices}

Among physician-administered injected and infused specialty drugs, the acquisition price of the drug paid by the provider (the price received by the supplying manufacturer-supplier prices) may differ substantially from the insurer reimbursement received by the provider (demand side prices). This divergence is largely due to Medicare and commercial insurers' reimbursement policies that imperfectly reflect the actual acquisition costs of these drugs.

On acquisition prices, NDA and ANDA sponsors (and in some cases, drug catalog publishers) set the wholesale acquisition cost (WAC) of a 
given drug irrespective of formulation. Wholesalers, retail pharmacies, and other purchasers generally acquire branded drugs from manufacturers at a modest discount off WAC (commonly a 1-2 percent prompt payment discount); generic drugs are typically discounted much more heavily off of WAC. Additional discounts from wholesalers or from manufacturers negotiated by retail pharmacies, by pharmacy benefit managers (PBMs), or by group purchasing organizations (GPOs) on behalf of their members may be directly related to a purchaser's volume or share of a drug within a therapeutic class and also over a bundle of drugs (Frank 2001). The ANDA sponsors of oral drugs can compete intensively on price to win GPO or PBM contracts, which in exchange offers the lowest priced manufacturer preferred formulary and copayment status. Generally, orally formulated anticancer and other selected specialty drugs are less prone than others to formulary based acquisition price negotiations because of the lack of perceived therapeutic substitutes (EMD Serono 2013; PBMI 2014). Physician-administered infused and/or injected drugs may not be prone to acquisition cost discounts related to preferred formulary and/or copayment status arrangements at all, but may be subject to volume-based purchaser discounts. In addition, purchasers of specialty oral and injected/infused drugs can be eligible for federally mandated "best-price" rebates off average manufacturer price (AMP) for Medicaid-insured patients, similar to nonspecialty drugs. The AMP is essentially the average price wholesalers and certain pharmacies pay for drugs distributed to retail community pharmacies (US Department of Health and Human Services [OIG] 2010).

Qualified outpatient hospital-based clinics, affiliated community-based clinics, and contract pharmacies are also able to purchase oral and injected/ infused drugs directly from manufacturers or wholesalers (but not via GPOs) at the federally mandated 340B Drug Pricing Program discounted price off AMP. The $340 \mathrm{~B}$ prices for branded drugs must be at least 23.1 percent discounted off of the AMP, but actual negotiated 340B prices are frequently lower than the 340B ceiling price (GAO 2011). Consequently, discounts through the 340B program have become a prominent part of supplier prices in the specialty and nonspecialty drug market. A recent analysis by Drug Channels (2014) suggests drug purchases under the 340B drug discount program have grown by 800 percent, from $\$ 0.8$ billion in 2004 to $\$ 7.2$ billion in 2013. In 2013, hospitals received 340B discounts on at least 25 percent of their drug purchases, compared with only 3 percent in 2004.

Insurers reimburse the use of the specialty drugs in two ways: via the pharmacy benefit (oral specialty drugs, similar to that of nonspecialty oral drugs) or the outpatient medical benefit (all physician-administered injected and infused drugs and a small number of oral drugs). Commercial insurers also provide coverage for Medicare-insured individuals using drugs covered under the pharmacy benefit ("Part D"). Commercial insurers that provide Part D coverage for prescription drugs are required to cover all drugs in six 
protected classes, one of which is anticancer drugs. This protection requires commercial insurers to offer pharmacy benefits to Medicare beneficiaries that include all available anticancer drugs, with limited supply-side access controls. Reimbursement for pharmacy benefit-covered drugs is generally considered to reflect acquisition costs (albeit imperfectly), other than the discounts obtained through the 340B program (PBMI 2014).

Medicare, the public insurance program providing virtually universal coverage to adults age sixty-five and older, is the most prominent payer for drugs covered under the outpatient medical benefit ("Part B"), followed by commercial insurers, and then state Medicaid agencies (MedPAC 2006). By law, neither Medicare nor Medicaid can consider the cost of drugs or cost effectiveness in coverage decisions (Neumann 2005). Consequently, Medicare and Medicaid cover all newly approved specialty drugs. Indeed, drugs to treat cancer accounted for a majority of outpatient Part B (i.e., largely infused and/or injected specialty) drug spending in 2004. While in theory private payers have more leeway to set coverage policies, de facto coverage (and reimbursement) policy for most specialty drugs follows that of Medicare's policies (Clemens and Gottlieb 2013).

Prior to 2006, Medicare reimbursed providers for purchasing and administering physician-administered specialty drugs as a percentage of the AWP: 95 percent from 1998 to 2003 and 85 percent in 2004. Enacted as part of the 2003 Medicare Drug Improvement and Modernization Act (MMA), Medicare instituted a new average sales price (ASP) payment system intended to more closely reflect actual acquisition prices than AWP, with two notable exceptions: Medicaid best prices and rebates, and 340B discounts. Effective January 2006, Medicare changed reimbursements for Part B drugs to the manufacturers' national ASP two quarters prior plus a 6 percent markup (Jacobson, Alpert, and Duarte 2012). The 2011 Budget Control Act reduced Medicare Part B reimbursement effective April 1, 2013, from ASP plus 6 percent to ASP plus 4.3 percent, where it remains currently. Recent industry reports suggest commercial insurance reimbursement may be more generous than ASP plus 4.3 percent (PBMI 2014).

These policies were responses to the widely recognized fact that reimbursement for many physician-administered specialty drugs covered under outpatient medical insurance benefits had been well in excess of their acquisition prices. Indeed, hospitals, many provider groups, and specialty pharmacy outlets profit from the gap between drugs' acquisition price and reimbursement by insurers and patients, often termed the "spread" (GAO 2004; Barr, Towle, and Jordan 2008; Barr and Towle 2011, 2012; Towle and Barr 2009, 2010; Towle, Barr, and Senese 2012). According to the GAO, prior to 2006 many drugs were available for purchase by provider groups at acquisition prices averaging 13 to 34 percent below their average wholesale price (AWP), while others - particularly generics - were acquired at even significantly lower prices, largely due to PBM and GPO pricing negotiations. 
Due to statutory exemptions, the spread can be substantial among drugs purchased under 340B discounts and Medicaid rebates for eligible patients.

By setting the ratio of drug reimbursement to ASP plus 6 percent through 2012 and ASP plus 4.3 percent thereafter, the MMA reform generated the largest reimbursement decline for physician-administered drugs in Medicare's history. For oncology drugs, the policy change represented a marked decline from the weighted average reimbursement-to-cost ratio of 1.22 in 2004, and an even larger decline relative to the years prior to the passage of the MMA when the AWP rather than ASP was used as the benchmark to measure costs (GAO 2004). Jacobson et al. (2010) plot payment rates for drugs commonly used to treat lung and other solid tumor cancers; they observe the payment change due to the MMA to be very dramatic for some drugs. However, the changes were heterogeneous, with some drugs facing no change and others even a slight increase.

Nevertheless, a 2006 survey of oncologists suggests those practicing in selected outpatient settings obtained 70 to 77 percent of their practice revenues from drug payments (Akscin, Barr, and Towle 2007). Later surveys using 2009-2011 data report over 50 percent of outpatient oncology practice revenues continued to be derived from the spread between drug acquisition costs, insurer reimbursements, and patient payments (Towle and Barr 2009, 2010; Towle, Barr, and Senese 2012). Due to these payment incentives, many outpatient specialty physicians, notably oncologists, report that they face financial incentives to administer chemotherapeutics with high "spread" (Malin et al. 2013). In addition, various studies suggest oncologists' drug choices are responsive to profit margins. Conti et al. (2012) found that the use of irinotecan decreased following patent expiration even though the price dropped by more than 80 percent, possibly reflecting declines in the spread between the reimbursement level and oncologists' acquisition cost. Jacobson et al. (2006, 2010) and Jacobson, Earle, and Newhouse (2012) find that oncologists switched away from drugs that lost the most margin after MMA reform implementation and toward expensive drugs favored by the equalized 6 percent markup across all drugs.

\subsection{The Model}

In this section, we outline our empirical models of ANDA sponsor entry as well as pricing and utilization effects among specialty drugs following LOE, grounding them in theoretical considerations.

\subsubsection{Theoretical Considerations and Empirical Findings for Entry Models}

Classic economic theory has much to say about firms' short-run decisions to invest in their capability to produce an undifferentiated product in the context of their cost, demand, and marginal revenue curves (Pindyck 
and Rubinfeld 2013). Notably, when the supply of production inputs is constrained and/or there are substantial fixed costs of entry, entry may be more limited than assumed in classical models (Tirole 1988; Mankiw and Whinston 1986; Bresnahan and Reiss 1988, 1991; Berry 1992). Berry and Reiss (2007) describe reduced-form and structural models where for any given product market, the number of entrant firms is a function of their fixed entry costs that may differ among firms based on their scale and scope, and potential revenues related to the demand elasticity for this product relative to available substitutes and other production opportunities.

In the pharmaceutical market context, a number of empirical studies have relied on this intuition to study firm entry after a drug's LOE. Reiffen and Ward (2005) examined generic entry using data on thirty-one drugs experiencing LOE in the late 1980s and early 1990s. They find that more generic firms enter and enter more quickly into markets when expected profits are greater. Scott Morton (2000) conducted a market-level analysis of eighty-one drugs undergoing LOE between 1986 and 1992, and found that drugs that have higher prepatent expiration revenues and that are used to treat highly prevalent chronic diseases experience greater generic entry. Scott Morton (1999) examined firm characteristics associated with generic entry decisions. Among drugs undergoing patent expiration between 1984 and 1994, she finds a generic firm's previous experience with a given type of drug formulation and therapeutic class increases the probability of similar subsequent generic entry. This work and others (Kyle 2006; Grabowski and Vernon 1992, 1996) suggest drug manufacturing economies of scope may be an important determinant of entry decisions. Outside the United States, Iizuka (2009) examines the relative importance of drug reimbursement policies on the number of generic entrants in Japan between 2004 and 2006. She finds fewer generic manufacturers enter markets when the drug is subject to administrative pricing policies (drugs commonly used in the hospital) compared to those that are not (drugs commonly dispensed in the outpatient setting).

Based on this literature, we implement descriptive reduced-form count models to examine molecule-specific, industry- and firm-level entry determinants in the specialty drug market. The base model we estimate is of the following general form:

$$
\text { Mancount }\left(\text { entrants }_{k}\right)=F\left(Z_{k} \delta+X_{i} \beta\right),
$$

where Mancount is the number of firms having an approved ANDA for a given molform, $Z_{k}$ is a matrix of characteristics of drug market $k$ that affect market size, while $X_{i}$ is a matrix of firm or molecule characteristics that predict the fixed cost of entry for firm $i$ into market $k$. Holding all else equal, we expect to observe more firms wanting to enter a market as potential market size increases and less firms entering drug markets where the manufacturing technology needed for production is highly specialized and entails large fixed 
costs. We assume regulatory cost differences among molecules are small and that we can control adequately for different manufacturing techniques for different product groups (Wiggins and Maness 2004; Caves, Whinston, and Hurwitz 1991; Grabowski and Vernon 1992, 1996). Year and year squared enter the model to help control for changes in regulatory and other fixed cost differences over time.

As discussed in the background section, the 2003 MMA altered reimbursement and benefit policy between 2004 and 2006 for many drugs in our sample, and therefore may have affected specialty market entry patterns (Iizuka 2009). Specifically, provisions of the MMA: (a) lowered Medicare reimbursement for Part B drugs from 95 percent of AWP to 85 percent of AWP effective January 2004 ("MMA1"); (b) provided Medicare coverage to pharmacy dispensed, largely orally formulated drugs in January 2006 (Medicare Part D) ("MMA2"); and (c) instituted the new ASP plus 6 percent payment scheme in January 2006 ("MMA2"). To mark these events, we define two 0-1 indicator variables MMA1 and MMA2 that take on the value of one after January 2004 and January 2006, respectively. We also create interaction variables MMA $1 *$ Part B and MMA $2 *$ Part B defined as the product of the MMA indicator variables and whether the molform was covered by Part B. We include these dummies in our manufacturer count models.

Furthermore, while the MMA1 and MMA2 policies targeted all drugs covered under Part B, the impact of these changes varied across drugs depending on the magnitude of the payment changes. Following Jacobson et al. (2010) and Jacobson, Alpert, and Duarte (2012), for each drug $j$, we compute the absolute value of the percentage change in reimbursement just before versus after the MMA1 reform, and call the variable "MMA1bite":

$$
\begin{aligned}
\text { MMAlbite } & =\text { Payment }_{j, 04-05} \\
& =\operatorname{Abs} \mid \log \left(\text { Payment }_{j, 05}\right)-\log \left(\text { Payment }_{j, 04}\right) \mid
\end{aligned}
$$

where Payment $j_{j 05}$ is the Medicare payment in quarter 1 of 2005 (based on ASP) for drug $j$ and Payment ${ }_{j, 04}$ is the Medicare payment in quarter 4 of 2004 (95 percent of AWP); this variable takes on identical nonzero values in 2005:Q1 and thereafter, and is zero before 2005:Q1. We focus on this one-quarter change for the first reform because it is plausibly exogenous to manufacturer supply decisions.

However, as noted earlier, we do not use these measures to derive welfare implications of entry under existing and alternative policy regimes (similar to that pursued by Berry [1992] and Berry and Reiss [2007]) given the host of agency, information, and moral hazard issues plaguing health care markets. Rather, as described in further detail below, we indirectly examine the welfare implications of LOE among these drugs by examining whether the neoclassical relationships among presumed price declines upon LOE and generic entry and volume increases hold. 


\subsubsection{Theoretical Considerations-Price and Use Models}

A number of empirical studies have relied on the framework proposed by Bresnahan and Reiss (1991) among others (Caves, Whinston, and Hurwitz 1991; Grabowski and Vernon 1992, 1996; Frank and Salkever 1997; Wiggins and Maness 2004) to examine the relationship between product prices and the number of suppliers. This framework posits a Cournot quantity-setting model or an entry threshold model (Bresnahan and Reiss 1991), predicting prices should initially fall quickly and then steadily, gradually approaching marginal cost as additional entry occurs. Bresnahan and Reiss (1991) examined prices for dentists, auto repair shops, and the like in geographically isolated county seats. They found prices decline significantly when the supplier count moves from two to three firms, with an even larger price impact observed moving from three to four firms, but smaller price impacts from subsequent entry; thus, they conclude that frequently it requires only three or four entrants to approximate competitive conditions in these markets. They also find a significant difference between price estimates in concentrated county seats and unconcentrated urban markets, suggesting local product market conditions are important in determining price declines. Similarly, Wiggins and Maness (2004) find continuing price declines among drugs undergoing LOE as the number of suppliers becomes large (more than five competitors). Reiffen and Ward (2005) find that generic drug prices fall with increasing number of competitors, but remain above long-run marginal costs until there are eight or more competitors. They also find the size and time paths of generic revenues and the number of firms are greatly affected by expected market size.

Several other authors have reported very small changes in price associated with entry into drug markets after LOE, and even price increases in some drug markets (Caves, Whinston, and Hurwitz 1991; Grabowski and Vernon 1992, 1996). Frank and Salkever (1992) developed a theoretical model to explain the anomaly of rising branded prices in the face of generic competition. Their model posits a segmented market where two consumer segments exist - a quality-conscious, brand-loyal segment that continues to buy the established branded drug after generic entry and a price-conscious segment that is less brand loyal. Frank and Salkever (1997) report that branded prices rise and generic prices fall in response to LOE and generic entry. Ellison et al. (1997) and Griliches and Cockburn (1994) also find that average branded anti-infective prices rise with generic entry; Ellison et al. (1997) and Aitken et al. (2013) report similar findings and also document significant price responsiveness between branded and generic drugs.

We draw on this literature to establish the plausibility of the presumed price drop following LOE among generic specialty drugs. Specifically, we first examine the relationship between supplier prices received by manufacturers (inflation-adjusted monthly total sales revenues/total extended unit 
use) and the number and nature (branded vs. generic) of firms supplying the market (Caves, Whinston, and Hurwitz 1991; Grabowski and Vernon 1992, 1996; Frank and Salkever 1997; Wiggins and Maness 2004; Reiffen and Ward 2005). We then examine the extent to which supplier prices of the generic drug across manufacturers fall with generic entry, using the following Cournot model:

$$
P *(n)=(a+c N) /(N+1),
$$

in which we assume a roughly linear relationship between price and the inverse of the number of sellers. Like others, here we assume that at any given point in time the number of approved suppliers, $N$, is exogenously determined reflecting FDA approval and timing uncertainty, and variability in reducing ANDA backlogs (Ellison et al. 1997; Scott Morton 1999, 2000; Wiggens and Maness 2004).

We then estimate reduced-form models of utilization after generic entry as the "dual" of the Cournot model of price competition in equation (2) (Grabowski and Vernon 1992, 1996; Berndt, Kyle, and Ling 2003; Knittel and Huckfeldt 2012) using generalized least squares. ${ }^{1}$ We estimate randomeffect regression models that quantify the importance of drug-specific demand and cost differences in influencing the use-supplier relationship (Wiggins and Maness 2004) having the following form:

$$
\ln Y_{k t}=\alpha+\beta_{t}+\kappa Z_{k}+\theta \operatorname{Post}_{k t}+\varepsilon_{k t},
$$

where $Y_{k t}$ is the utilization volume of $\operatorname{drug} k$ at month $t, \alpha$ is a constant, $\beta_{t}$ are time fixed effects capturing general changes in specialty drug demand, and $\kappa Z_{k}$ are effects from the characteristics of the molecule formulation ("molform" characteristics). The variable Post t $_{k t}$ is an indicator variable denoting generic entry month-year for each molform experiencing postLOE generic entry in the sample. Positive estimates of $\theta$ suggest volume increases post-LOE (presumably, reflecting increased quantity demanded from lower average molecule price post-LOE), whereas negative estimates suggest utilization declines post-LOE.

To interpret the hypothesized result (finding that $\theta<0$ in equation [3]), we include in one specification whether LOE has an independent and negative effect on usage among physician-administered drugs after LOE, all else equal. In addition, LOE should act to induce institutional consumers to shift their demand away from low-cost generic specialty drugs toward highpriced branded alternatives when the drug is covered under insurers' outpatient medical benefit (where the absolute value of insurer reimbursement would be greater, holding all else constant) (Jacobson et al. 2010; Jacobson, Earle, and Newhouse 2012; Conti et al. 2012). We identify these independent

1. Duggan and Scott Morton (2010) and Berndt and Aitken (2011) have found significant volume increases related to policy changes that act to decrease drug prices to consumers. 
effects on use by including in the model the variables that capture Medicare coverage in Part B and the MMA reimbursement and coverage changes outlined above.

\subsubsection{Theoretical Considerations-Shortage Models}

Our monthly data cover the 2001-2007 time period. Widespread drug shortages did not occur in the United States until after 2008. However, consistent with economic theory, our data can be uniquely used to consider two aspects of the market for drugs preceding incident shortage reports. First, among our sample drugs we examine the correlation between shortage reports at the molform level and the number of manufacturers manufacturing these drugs in 2007:Q4. Second, we examine whether 2007:Q4 molecule revenues, and/or Medicare reimbursement and their reforms implemented between 2001 and 2007 are associated with shortage reports among our sample of specialty drugs, reflecting reduced incentives to maintain manufacturing quality standards.

\subsection{Data and Descriptive Trends}

We obtained national monthly data on the use, volume, and retail and nonretail dollar sales of all specialty drugs by distributor from IMS Health Incorporated's National Sales Perspectives ${ }^{\mathrm{TM}}$ (NSP) database covering periods between January 2001 and December 2007. The NSP data have been used in numerous published studies of pharmaceutical revenues and volumes. The NSP data derive from a projected audit describing 100 percent of the national unit volume and dollar sales in every major class of trade and distribution channel for US prescription pharmaceuticals. The NSP sample is based on over 1.5 billion annual transactions from over 100 pharmaceutical manufacturers and more than 700 distribution centers. The NSP provides information on the molecule-specific chemical and branded names, route of administration, strength, and the name of distributing firm(s). Each firmmolecule-formulation-strength (hereafter, "molform strength") is uniquely identified in the data set by its eleven-digit National Drug Code (NDC).

"Dollar sales" measures the amount of funds retail pharmacies, mail pharmacies, nonfederal hospitals, federal facilities, long-term care facilities, clinics, home health care facilities, and miscellaneous facilities spent on a drug acquired from manufacturers and drug wholesalers. The prices reflected in this sales measure are the actual invoice prices outlets (e.g., pharmacies, hospitals, clinics) pay for the products, whether purchased directly from a manufacturer or indirectly via a wholesaler or chain warehouse. Invoice line item discounts are included, but prompt-payment discounts and bottom-line invoice discounts are not included. Rebates, typically paid by the manufacturer directly to a customer, insurer, or PBM are not reflected in these data. Dollar sales are converted into 2012 US dollars using the 
Count of unique sample NDCs by therapeutic class

\begin{tabular}{lrrrrrrr}
\hline & \multicolumn{7}{c}{ Count of unique NDCs by anatomic therapeutic } \\
& \multicolumn{7}{c}{ class designation } \\
\cline { 2 - 8 } ATC & 2001 & 2002 & 2003 & 2004 & 2005 & 2006 & 2007 \\
\hline A04 antiemetcs + antinauseants & 247 & 240 & 258 & 273 & 259 & 289 & 328 \\
L01A alkylating agents & 68 & 70 & 72 & 78 & 80 & 72 & 81 \\
L02B antimetabolites & 117 & 114 & 114 & 120 & 125 & 128 & 130 \\
L01C vinca alkaloids & 55 & 59 & 66 & 67 & 75 & 73 & 67 \\
L01C antineoplas. antibiotics & 82 & 87 & 83 & 82 & 80 & 90 & 115 \\
L01X all other antineoplastics & 40 & 42 & 53 & 91 & 107 & 121 & 133 \\
L02A cytostatic hormones & 63 & 64 & 67 & 73 & 74 & 75 & 74 \\
L02B cyto hormone antagonists & 22 & 29 & 49 & 52 & 54 & 55 & 55 \\
L04X other immunosuppressants & 0 & 0 & 0 & 0 & 0 & 12 & 12 \\
V03D detox ag a-neoplast. trmt. & 58 & 56 & 46 & 46 & 51 & 51 & 49 \\
Grand total & 752 & 761 & 808 & 882 & 905 & 966 & 1,044 \\
\hline
\end{tabular}

Consumer Price Index for All Urban Consumers (CPI-U) inflation calculator. "Extended units" measures the number of single items (such as vials, syringes, bottles, or packets of tablets/capsules) contained in a unit or shipping package purchased by providers and pharmacies, and may include varying available doses and strengths.

Our NSP data covers the following ten World Health Organization's four-digit cancer-related anatomic therapeutic classes (ATCs): antiemetics and antinauseants (A04A), alkylating agents (L01A), antimetabolites (L01B), vinca alkaloids (L01C), antineoplastic antibiotics (L02D), all other antineoplastics (L01X), cytostatic hormones (L02A), cytostatic hormone antagonists (L04B), other immune suppressants (L04X), and detox ag a-neoplastic treatments (V03D). This sample frame has the advantage of including branded and generic versions of the same molecule having similar manufacturing requirements, and including drugs that are covered under both insurers' pharmacy and medical benefits. The ATC four-digit and more disaggregated ATC class designations are retained and coded for use in the analysis.

The distribution of NDCs by ATC class is listed in table 9.1. The majority of drugs in the full sample fall into several categories: drugs used to treat cancer (antimetabolites, antineoplastics agents, other antineoplastic treatments-215 of 752 in 2001, 312/1,044 in 2007), supportive therapy (antiemetics and antinauseants, cytostatic hormones, cytostatic hormone antagonists - 332/752 in 2001, 457/1,044 in 2007) and other (other immune suppressants, antineoplastic antibiotics - 82/752 in 2001, 127/1,044 in 2007).

According to economic theory, pre-LOE differences in fixed costs affect the subsequent number of generic entrants. Therefore, similar to Scott Morton (1999, 2000), Iizuka (2009), and Wiggins and Maness (2004), we code 
formulations into several categories according to the type of specialized equipment needed to manufacture a drug and the cleanliness standards required in the manufacturing facility (oral solid tablets or capsules; injectable or infusible products; topical preparations; and other formulations, including ocular drugs, patches, and aerosols).

For each molecule, the earliest ANDA approval for each molform was identified using the FDA's comprehensive online listing. This method stratified the full sample (166 molforms) into three groups: (a) forty-one molforms ( 25 percent of full sample) experiencing initial generic entry between January 2001 and July 2007, (b) fifty molforms (30 percent) experiencing generic entry prior to January 2001, and (c) seventy-five molforms (45 percent) only available as exclusively marketed "brands" between January 2001 and December 2007 (appendix table 9A.1). Because of our focus on the extent and impact of generic entry, we excluded molforms in the (c) category from our analyses (all molforms are listed in appendix table 9A.2).

Among the forty-one molforms experiencing generic entry in our study period, the majority underwent LOE in 2002 and 2004 (appendix table 9A.2). Nine (22 percent) underwent generic entry on or following January 2006. Sixty-one percent (twenty-five out of forty-one molforms) had FDA-approved labels that indicated their use in combination therapy to treat cancer. Among this sample, we observed the following drug formulation pattern: 37 percent oral and 63 percent infused/injected or otherwise physician administered. Our check of Part B Medicare reimbursement schedules revealed 76 percent (thirty-one of our forty-one molforms experiencing initial LOE between 2001 and 2007) were covered by the Medicare Part B benefit (the remainder presumably covered under Part D benefits) (CMS 2014).

Using the FDA's comprehensive online listing we identified whether, for a given molecule, generic entry timing differed by formulation and/or strength. The subsequent entry of differing formulations (and/or strengths) among existing ANDAs may reflect a different underlying demand structure than with novel entrants, with the more commonly utilized formulations/ strengths being produced earliest. We found that the majority of molecules undergoing generic entry shared identical entry dates across multiple formulations; yet, a limited number of molforms experienced sequential entry by different strengths. Consequently, in our empirical models we estimate parameters first at the molform level and in sensitivity analyses at the molform-strength level.

The number of "manufacturers" for each molform and molform strength was identified using the NSP and was cross-checked using the FDA's Orange Book. We identified sixty-three manufacturers distributing at least one cancer drug undergoing initial generic entry in our study period. In appendix table 9A.3, we enumerate these manufacturers and the total number of molforms produced by them among all drugs in the parent sample. As expected 
Table 9.2

Number of all sample cancer drugs produced by top ANDA sponsors; number of cancer drugs produced by top manufacturers of drugs undergoing LOE

\begin{tabular}{ccccc}
\hline & APP & Bedford Labs & Teva Parenteral Me & Teva Pharmaceuticals \\
\hline 2001 & & 16 & & 9 \\
2002 & & 15 & & 9 \\
2003 & 12 & 16 & 20 & 12 \\
2004 & 16 & 20 & 19 & 14 \\
2005 & 17 & 21 & 22 & 15 \\
2006 & 16 & 23 & 22 & 18 \\
2007 & 20 & 26 & & 19 \\
\hline
\end{tabular}

from our institutional review, we find production of these drugs concentrates in several manufacturers. Branded manufacturers of drugs undergoing LOE in our sample are primarily limited to the following: Abbott, AstraZeneca, Bayer Healthcare, Bristol-Myers Oncology, Genzyme, GSK, Novartis, Pfizer, Roche, and Watson. Among generic manufacturers, APP, Bedford Laboratories, Teva Parenteral Me, and Teva Pharmaceuticals dominate the production of drugs undergoing initial LOE in our sample. We also observe growth in the commitment of these ANDA sponsors to the production of all generic cancer drugs over time, as the number produced is generally larger in 2007 than in earlier years, although year-to-year changes are occasionally negative (table 9.2). We use these branded/generic manufacturer designations for examining pricing trends at the molform-manufacturer level after LOE.

We construct measures of prepatent expiration brand revenues and $l n$ revenues, adopting a definition of "market" size consisting of sales only by the branded molecule in the four complete quarters prior to LOE (average monthly revenue $=439,000$ [standard deviation $=452,000$, min. $=0$, max. $=1,722$ ]; average $\ln$ revenue $=5.6$ [standard deviation $=6.2$, min. $=0$, $\max$. = 13.2]) (Frank and Salkever 1997; Scott Morton 1999; Iizuka 2009). Following Scott Morton (1999), we also constructed a measure of the difference in revenue defined as the value of the difference between the revenue potential from the entry opportunity relative to that of the manufacturers' existing mean generic NDC portfolio from all drugs enumerated in the NSP (monthly average $=381,600$, standard deviation $=538,000, \mathrm{~min} .=-816$, max. $=1,599)$. To the extent firms' existing portfolios consist of old vintages of off-patent drugs having declining sales and the entry being considered is that for a widely utilized newer molecule having large sales volume, we expect this difference measure will positively affect probability of current entry. We transform by using the difference $\log$ form of this measure (monthly average $=5.9$, standard deviation $=1.5, \min .=-2.5, \max .=7.4)$ in the estimated model and its square. 
While previous literature has focused on using pre-LOE revenues (and its square, both typically log transformed) as measures of potential market size post-LOE, we augment these by constructing a measure reflecting the number of distinct conditions treated by the medicines. Specifically, we construct a measure of indication count, inclusive of FDA on-label approved and off-label Medicare reimbursed, measured in the year prior to LOE that is likely correlated with potential future revenues. ${ }^{2}$ The number of indications for which an NDC was reimbursed for use in the US population in each year (average $=6$, standard deviation $=9$ ) is taken from the Micromedex DrugDex Evaluations database, one of several compendia approved by Congress to guide CMS reimbursement policy (Conti et al. 2012). This identified FDAapproved (on-label) and off-label indications that were contemporaneously reimbursed by the Centers for Medicare and Medicaid Services.

Finally, we matched all sample molforms and molform strengths with the University of Utah Drug Information Service to determine dates of any shortages, including resolved shortages, if present. ${ }^{3}$ No sample molforms and molform strengths were reported in short supply between January 2001 and December 2007.

\subsection{Results}

\subsubsection{Count Models for Descriptive Purposes}

Bearing in mind the caveats on manufacturer counts created by the presence of considerable contract manufacturing activities, we first describe the average number of generic manufacturers per molform experiencing LOE by year of LOE (figure 9.1). We observe the average number to range between 1.66 and 4.9 manufacturers over all years, and what appears to be an upward trend in entry count in 2006 and 2007 compared to previous years, from a low of 1.66 in 2003 to a high of 4.9 in 2007.

Furthermore, average entrant counts differ by drug formulation: oral drugs exhibit an average of 6.26 (standard deviation $=2.7$, $\max =11$ ) manufacturers entering after LOE, while physician-administered drugs exhibit an average of 4.5 (standard deviation $=2.7, \max =9$ ) manufacturers entering after LOE.

To place these observations into wider industry-level context, we also calculated the average number of manufacturers of always generic cancer drugs available throughout the study period (appendix table 9A.2; figure 9.2). We

2. Incentives for manufacturers to seek additional indications for reimbursements diminish considerably after LOE, although the off-patent brand may pursue a "branded generic" strategy in which it markets a combination product consisting of the off-patent brand and a generic drug.

3. http://www.ashp.org/drugshortages/current/; http://www.ashp.org/menu/DrugShortages/ ResolvedShortages. 


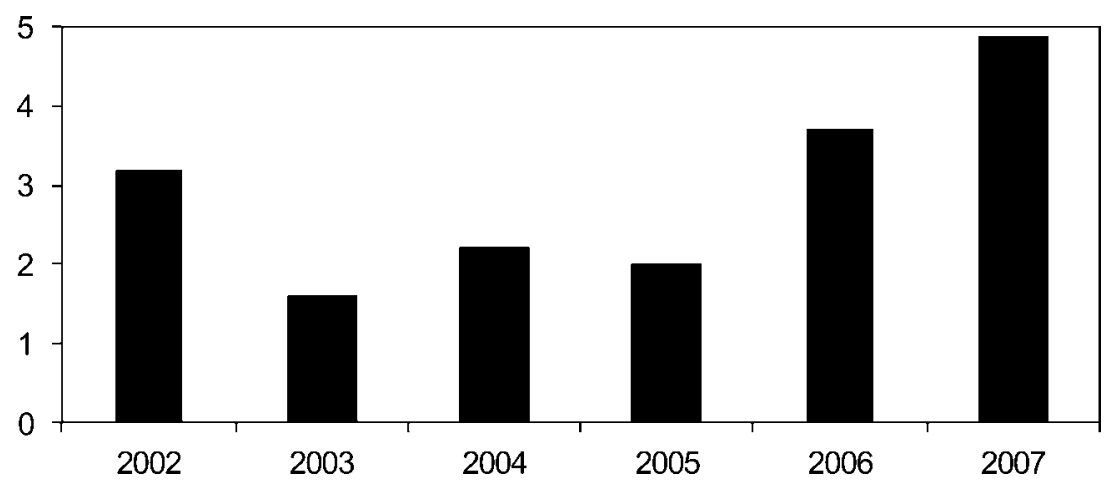

Fig. 9.1 Average number of ANDA sponsors entering a new molform after LOE, by year of LOE

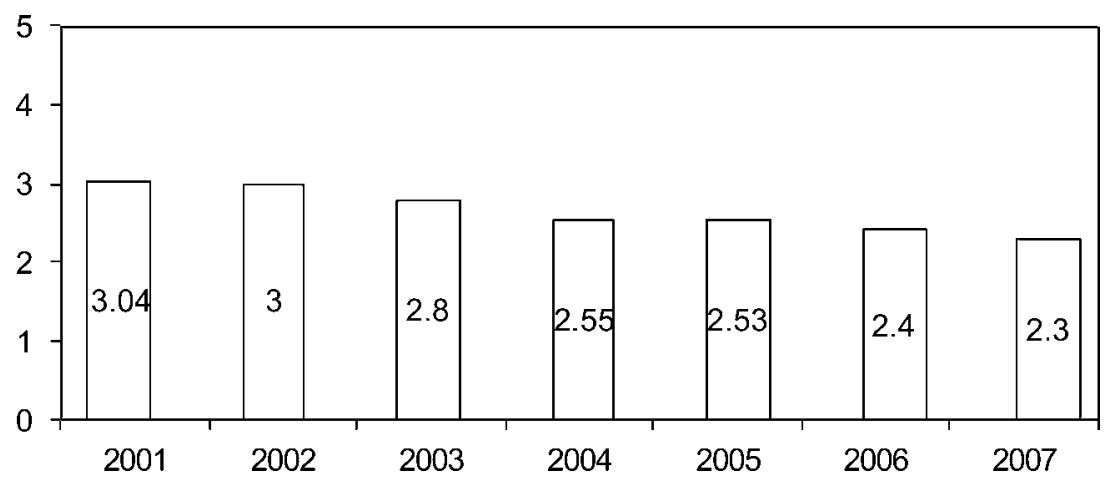

Fig. 9.2 Average number of manufacturers producing always generic molforms

observe the average number of manufacturers producing these drugs to be declining gradually but steadily from 3.04 in 2001 to 2.3 in 2007.

Interestingly, the patterns of entry and exit among specialty cancer drugs undergoing LOE during our study periods appear quite diverse, as is illustrated in the various panels of table 9.3. For example, the first column (Example 1) in table 9.3 documents a situation in which the innovator brand manufacturer (Pierre Fabre Pharma, bolded) continues to market vinorelbine IAC in injectable and intravenous formulations following LOE in 2003 and throughout the remaining study period. We also observe injectable and intravenous formulation ANDA entry in vinorelbine IAC by Baxter Pharma Division and Sicor Pharma in 2003, Bedford Labs and Teva Parenteral ME in 2004, and APP and Hospira in 2005. We observe Sicor Pharma exiting this drug market in 2004 and Baxter Pharm Division exiting in 2007. Merger and acquisition activity likely explains the apparent exit by Sicor Pharma and entry by Teva Parenteral ME in 2004 (table 9.4) — Teva acquired Sicor 


\begin{tabular}{|c|c|c|c|}
\hline \multirow[b]{2}{*}{ Year } & \multirow{2}{*}{$\begin{array}{c}\text { Example 1: Innovator } \\
\text { stays in the market after } \\
\text { LOE } \\
\begin{array}{c}\text { Vinorelbine IAC inject, } \\
\text { IV }\end{array}\end{array}$} & \multicolumn{2}{|c|}{ Example 2: Innovator exits the market after LOE } \\
\hline & & $\begin{array}{c}\text { Carboplatin IAC inject, } \\
\text { IV Reg. }\end{array}$ & $\begin{array}{c}\text { Tamoxifen } 0511 \text { orals, } \\
\text { sol. tab/cap RE }\end{array}$ \\
\hline 2001 & Pierre Fabre Pharm & Bristol-Myers Oncology & AstraZeneca \\
\hline 2002 & Pierre Fabre Pharm & Bristol-Myers Oncology & $\begin{array}{l}\text { AstraZeneca } \\
\text { Barr Labs }\end{array}$ \\
\hline 2003 & $\begin{array}{l}\text { Baxter Pharm Div } \\
\text { Pierre Fabre Pharm } \\
\text { Sicor Pharm }\end{array}$ & Bristol-Myers Oncology & $\begin{array}{l}\text { AstraZeneca } \\
\text { Barr Labs } \\
\text { Mylan } \\
\text { Roxane } \\
\text { Teva Pharm }\end{array}$ \\
\hline 2004 & $\begin{array}{l}\text { Baxter Pharm Div } \\
\text { Bedford Labs } \\
\text { Pierre Fabre Pharm } \\
\text { Teva Parenteral Me }\end{array}$ & $\begin{array}{l}\text { APP } \\
\text { Baxter Pharm Div } \\
\text { Bedford Labs } \\
\text { Bristol-Myers Oncology } \\
\text { Hospira } \\
\text { Teva Parenteral Me } \\
\text { Watson Labs }\end{array}$ & $\begin{array}{l}\text { AstraZeneca } \\
\text { Barr Labs } \\
\text { Mylan } \\
\text { Roxane } \\
\text { Teva Pharm } \\
\text { Watson Labs }\end{array}$ \\
\hline 2005 & $\begin{array}{l}\text { APP } \\
\text { Baxter Pharm Div } \\
\text { Bedford Labs } \\
\text { Hospira } \\
\text { Pierre Fabre Pharm } \\
\text { Teva Parenteral Me }\end{array}$ & $\begin{array}{l}\text { APP } \\
\text { Baxter Pharm Div } \\
\text { Bedford Labs } \\
\text { Bristol-Myers Oncology } \\
\text { Cura Pharm } \\
\text { Hospira } \\
\text { OTN Pharm } \\
\text { Teva Parenteral Me } \\
\text { Watson Labs }\end{array}$ & $\begin{array}{l}\text { AstraZeneca } \\
\text { McKesson Pkg Serv } \\
\text { Mylan } \\
\text { Ranbaxy Pharm } \\
\text { Roxane } \\
\text { Teva Pharm } \\
\text { Watson Labs }\end{array}$ \\
\hline 2006 & $\begin{array}{l}\text { APP } \\
\text { Baxter Pharm Div } \\
\text { Bedford Labs } \\
\text { Hospira } \\
\text { Pierre Fabre Pharm } \\
\text { Teva Parenteral Me }\end{array}$ & $\begin{array}{l}\text { APP } \\
\text { Baxter Pharm Div } \\
\text { Bedford Labs } \\
\text { Cura Pharm } \\
\text { Hospira } \\
\text { OTN Pharm } \\
\text { Teva Parenteral Me } \\
\text { Watson Labs }\end{array}$ & $\begin{array}{l}\text { A-S Medication } \\
\text { AstraZeneca } \\
\text { McKesson Pkg Serv } \\
\text { Mylan } \\
\text { Roxane } \\
\text { Teva Pharm } \\
\text { Watson Labs }\end{array}$ \\
\hline 2007 & $\begin{array}{l}\text { APP } \\
\text { Bedford Labs } \\
\text { Hospira } \\
\text { Pierre Fabre Pharm } \\
\text { Teva Parenteral Me }\end{array}$ & $\begin{array}{l}\text { APP } \\
\text { Baxter Pharm Div } \\
\text { Bedford Labs } \\
\text { Cura Pharm } \\
\text { Generamedix } \\
\text { Hospira } \\
\text { OTN Pharm } \\
\text { Teva Parenteral Me } \\
\text { Watson Labs }\end{array}$ & $\begin{array}{l}\text { A-S Medication } \\
\text { McKesson Pkg Serv } \\
\text { Mylan } \\
\text { Roxane } \\
\text { Teva Pharm } \\
\text { Watson Labs }\end{array}$ \\
\hline
\end{tabular}


Consolidation activity among firms in our sample

\begin{tabular}{|c|c|c|c|}
\hline & Merging firm & Acquiring firm & $\begin{array}{c}\text { Completion } \\
\text { year }\end{array}$ \\
\hline 1 & GREENSTONE LTD. & PFIZER & 2003 \\
\hline 2 & ABBOTT PHARM PRODS. & HOSPIRA & 2004 \\
\hline 3 & SICOR PHARM & TEVA PHARM & 2004 \\
\hline 4 & Mayne Pharm & HOSPIRA & 2007 \\
\hline 5 & Abraxis Pharm & APP & 2007 \\
\hline $6^{\mathrm{a}}$ & King & JHP PHARM & 2007 \\
\hline 7 & BARR LABS & TEVA PHARM & 2008 \\
\hline 8 & APP & Fresenius & 2008 \\
\hline 9 & Wyeth Ayerst & PFIZER & 2009 \\
\hline 10 & Medimmune Oncology & ASTRAZENECA & 2013 \\
\hline
\end{tabular}

Note: Capitalized manufacturer names indicate manufacturers producing drugs undergoing LOE in our sample.

${ }^{\text {a }} \mathrm{JHP}$ was formed out of assets from King and other companies.

in 2004, and likely subsequently consolidated the two generic products into one market offering.

In other cases, the innovator brand is observed to exit the molform market after initial LOE, as is seen in Example (2) of table 9.3. Here, the manufacturer of the branded version of carboplatin IAC injectable and regular intravenous (Bristol-Myers Oncology, bolded) faced LOE in 2004 and remained in the market only through 2005. In 2004 we observe APP, Baxter Pharma Division, Bedford Labs, Cura Pharm, Hospira, Teva Parenteral ME, and Watson Labs and in 2005 OTN Pharmaceutical entering this molform market. The final column of table 9.3 documents a somewhat similar pattern of exit by the innovator brand manufacturer (AstraZeneca, bolded) for the oral anticancer drug tamoxifen, albeit in 2007, several years after LOE in 2002, and staggered ANDA entry by Barr Labs, Mylan, Roxane, Teva Pharmaceuticals, and Watson Labs in 2004, McKesson Pkg. Serv. in 2005, and A-S Medication in 2006. Here too, the observed Barr Labs exit from this molform in 2005 might be related to the formalization of its acquisition by Teva several years later (see table 9.4).

These observations suggest mergers and acquisitions among generic firms (horizontal consolidation) and branded firms (vertical consolidation) that occurred between 2000 and 2009 could alter our results of manufacturer count entry. To check, we identified mergers and acquisitions among manufacturers using the SDC Platinum, a collection of databases on companies registered in the United States and a product of Thomson Reuters Financial Securities Data available through the University of Chicago's electronic library. This categorization was double checked using a search of all manufacturers and the trade press. The presence, date, and type of consolidation are reported in table 9.4 . 
To analyze factors contributing to the diverse entry patterns, we estimated random effects generalized least squares count models with ln mancount (log number of manufacturers) as the dependent variable for each molform based on the 2001-2007 pooled cross-section and time-series data; in sensitivity analyses, we reestimate using molform strength as the unit of observation. Since with a Poisson model there was overdispersion (estimated variance greater than mean), estimates presented in table 9.5 are based on the negative binomial model. Consistent with the raw averages, we observe less entry into injectable formulations after LOE (all models). There is also greater entry into the cancer therapeutic class and less entry into other classes after LOE (all models). Another robust finding across models is that $\ln$ preentry revenue positively affects the number of manufacturers. Consistent with this finding, we also observe in each of the estimated models the greater the number of $\ln$ indications for which the molform is recommended, the greater the number of manufacturers of that molform (models 1-5). However, $\ln$ preentry revenue squared flips in sign across models. Models $3-5$ report another modestly robust finding that when $\ln$ revenues of the candidate molform is much greater than the mean revenue per product of the incumbent portfolio of molform products (a positive ln revenue difference), the number of manufacturers for a molform increases, although the negative estimated coefficient on the squared $\ln$ revenue difference variable indicates this positive impact declines as the $\ln$ revenue difference increases. This suggests that all else equal, firms may face a trade-off as they contemplate additional generic entry between incremental revenue gained and the greater fixed and/or sunk production costs incurred from additional entry. Finally, note that while in models 4-5 the positive estimated coefficient on the month post-MMA1 indicator variable and the negative estimate on the post-MMA1 * Part B-covered interaction variable have the expected signs suggesting MMA reimbursement policy changes affected manufacturer entry, these estimates are not statistically significant.

\subsubsection{Supplier Prices following LOE}

As an initial analysis of the impact of LOE on supplier prices, we examine two measures or average monthly inflation-adjusted prices-prices and $\ln$ prices - separately for oral and injectable/infusible molforms, before LOE and generic entry and after LOE and generic entry, aggregated over brand and generic versions for each molform. As is seen in table 9.6, regardless of which price measure is used, average monthly prices are lower post-LOE and generic entry than pre-LOE for all drug formulations. Interestingly, aggregate price declines appear to be larger among physician-administered infused/injected drugs (38-46.4 percent) than among orally formulated drugs (25-26 percent).

Next, to examine the relationship between supplier prices following LOE and the number of manufacturers, we first plotted average monthly ln prices 


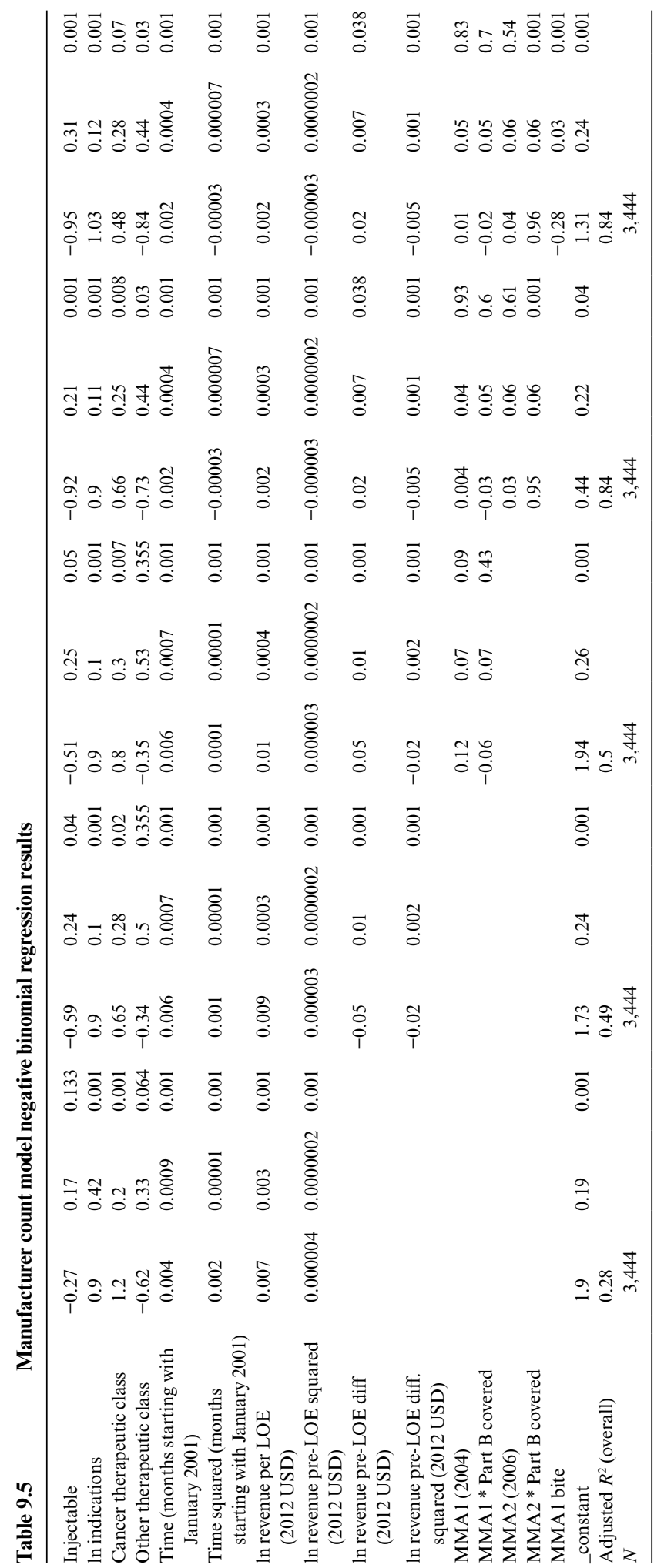

You are reading copyrighted material published by University of Chicago Press. Unauthorized posting, copying, or distributing of this work except as permitted under 
Raw inflation-adjusted prices and In prices before and after LOE

\begin{tabular}{|c|c|c|c|c|c|c|c|}
\hline & \multicolumn{2}{|c|}{ Before LOE } & \multicolumn{2}{|c|}{ After LOE } & \multicolumn{3}{|c|}{ After - before } \\
\hline & $\begin{array}{l}\text { Monthly } \\
\text { average }\end{array}$ & $\begin{array}{l}\text { Std. } \\
\text { error }\end{array}$ & $\begin{array}{l}\text { Monthly } \\
\text { average }\end{array}$ & $\begin{array}{l}\text { Std. } \\
\text { error }\end{array}$ & Difference & $\begin{array}{l}\text { Std. } \\
\text { error }\end{array}$ & $\begin{array}{l}\text { Percent } \\
\text { change }\end{array}$ \\
\hline \multicolumn{8}{|l|}{ Oral $(n=15)$} \\
\hline Prices (2012 USD) & 1.26 & 0.03 & 0.93 & 0.01 & -0.33 & 0.35 & -26 \\
\hline ln prices (2012 USD) & 0.57 & 0.016 & 0.43 & 0.037 & 0.14 & 0.01 & -25 \\
\hline \multicolumn{8}{|l|}{$\begin{array}{l}\text { Physician-administered } \\
\quad \text { infused/injected }(n=26)\end{array}$} \\
\hline Prices (2012 USD) & $1,356.1$ & 27.8 & 1985.5 & 30.3 & 629.42 & 41.1 & -46.4 \\
\hline ln prices (2012 USD) & 2.4 & 0.03 & 1.3 & 0.02 & 0.9 & 0.04 & -38 \\
\hline
\end{tabular}

Note: Bold = significant at the 1 percent level.

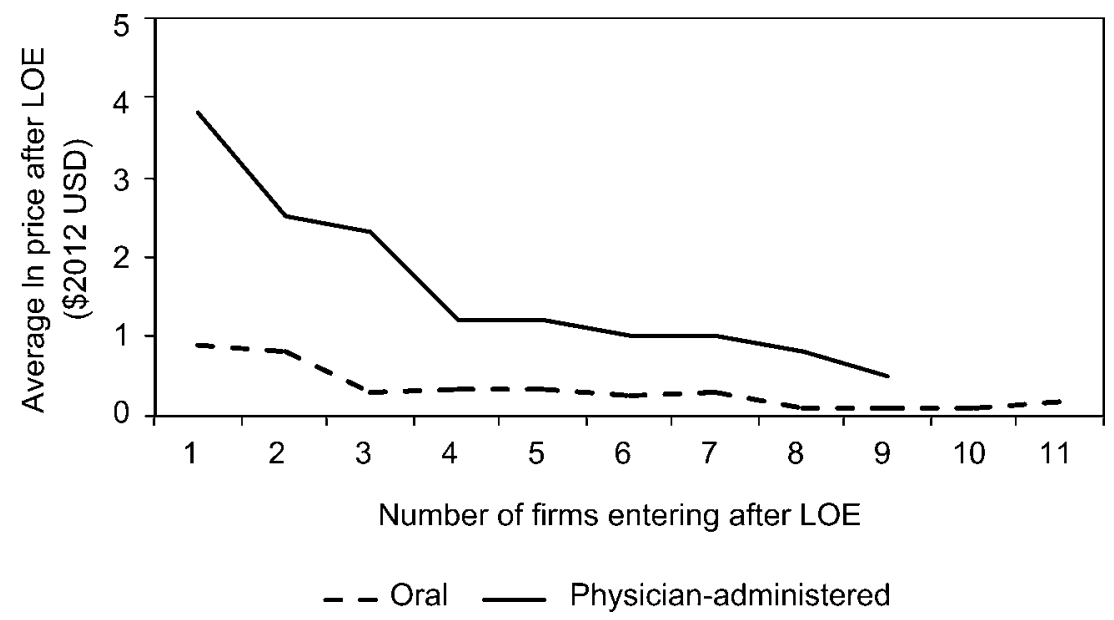

Fig. 9.3 Relationship between In inflation-adjusted estimated supplier prices (2012 USD) and manufacturer count after LOE

(2012 USD) observed in the last quarter of 2007 against the total number of unique entrants in all years following LOE (including the innovator brand), stratified by oral versus infused/injected or otherwise physician-administered formulation. Results are displayed in figure 9.3, with ln supplier prices on the vertical axis and total number of unique manufacturers following LOE on the horizontal axis. Two sets of results are striking. First, the level of ln prices for oral formulations is much lower than that for infused/injected or otherwise physician-administered drugs, up until there are about nine unique manufacturers of the formulation. Second, for infused/injected or otherwise physician-administered drugs, when the number of manufacturers increases from one to two, average ln prices fall about 25-30 percent, there is another even larger proportional drop in ln price as the number 
Relationship between inflation-adjusted supplier price (2012 USD) and manufacturer counts, by formulation and LOE status

\begin{tabular}{|c|c|c|c|c|c|c|}
\hline & \multicolumn{3}{|c|}{ Oral molforms } & \multicolumn{3}{|c|}{$\begin{array}{l}\text { Injected and infused or otherwise } \\
\text { physician-administered } \\
\text { formulated molforms }\end{array}$} \\
\hline & Coefficient & $\begin{array}{l}\text { Std. } \\
\text { error }\end{array}$ & $\begin{array}{c}p- \\
\text { value }\end{array}$ & Coefficient & $\begin{array}{l}\text { Std. } \\
\text { error }\end{array}$ & $p$-value \\
\hline \multicolumn{7}{|l|}{ Generic, underwent LOE } \\
\hline $\ln$ mancount & -0.77 & 0.03 & 0.0001 & -0.22 & 0.017 & -12.54 \\
\hline In mancount squared & -0.01 & 0.005 & 0.051 & 0.02 & 0.004 & 0.0001 \\
\hline Year & 0.26 & 0.05 & 0.001 & -0.29 & 0.03 & 0.0001 \\
\hline$N$ & 287 & & & 1,678 & & \\
\hline Adjusted $R^{2}$ & 0.16 & & & 0.12 & & \\
\hline \multicolumn{7}{|l|}{ Branded, underwent LOE } \\
\hline ln mancount & 0.07 & 0.02 & 0.0002 & 0.49 & 0.04 & 0.0001 \\
\hline ln mancount squared & 0.07 & 0.05 & 0.0001 & -0.04 & 0.006 & 0.0001 \\
\hline Year & -0.52 & 0.04 & 0.0001 & 0.26 & 0.04 & 0.0001 \\
\hline$N$ & 161 & & & 1,318 & & \\
\hline Adjusted $R^{2}$ & 0.12 & & & 0.05 & & \\
\hline
\end{tabular}

of manufacturers increases from three to four, but in the range between four and seven manufacturers, ln prices of these drugs are relatively stable, and after that as additional manufacturers of infused/injected or otherwise physician-administered drugs enter, the average ln price continues to fall. This suggests that for infused/injected or otherwise physician-administered cancer drugs, unlike the case for oral solids, price declines accelerate as the number of manufacturers increases.

A more rigorous method for analyzing the relationship between supplier prices following LOE and the total number of manufacturers (but bearing in mind potential measurement error in manufacturer counts from unobserved and time-varying outsourcing to contract manufacturing organizations) is via regression analysis. Results of estimating a regression equation via ordinary least squares with $\ln$ inflation-adjusted supply price as the dependent variable are presented separately in table 9.7 for generic and branded formulations following LOE, and for oral and infused/injected or otherwise physician-administered formulations.

We begin with the oral molforms. As seen in the top-left panel, following LOE generic prices fall sharply as $\ln$ mancount (which now includes only ANDA holders, not the brand) increases, and this decline accelerates ever so slightly as the square of $\ln$ mancount increases. Holding $\ln$ mancount and its square constant, prices increase annually (year $=1$ in 2001, 2 in 2002 , etc.). For the off-patent but branded oral molforms following LOE (bottom-left panel), the relationship of supplier prices with ln mancount is very different. Specifically, $\ln$ inflation-adjusted supplier prices of branded 
oral molforms increase with growth in $\ln$ mancount, and this price increase accelerates with the square of ln mancount, suggesting that for oral brands, the ability to differentiate themselves from generics post-LOE enables them to continue commanding premium prices. However, this ability to increase price declines with time, other things equal, as the estimated coefficient on the year variable is negative, large, and significant.

By contrast, as seen in the top-right corner of table 9.7, for injected and infused molforms following LOE, In inflation-adjusted supplier prices fall much less steeply as $\ln$ mancount increases than do oral molforms, and this price decline decelerates as the square of $\ln$ mancount increases; however, ln inflation-adjusted supplier prices fall as time increases. The situation is very different for branded injected and infused molforms following LOE (bottom-right panel): prices of these branded nonoral formulations increase with $\ln$ mancount, but at a decreasing rate (the estimate on the squared $\ln$ mancount variable is negative and significant). In summary, for both oral and injected/infused molforms, following LOE prices of generic molforms fall as $\ln$ mancount increases (with the price decline being much steeper for oral than injected/infused formulations), but for branded molforms following LOE, prices increase as $\ln$ mancount grows, with the price increase being steeper for injected/infused than oral formulations. These results suggest post-LOE price competition among suppliers is less intense for injected/ infused than oral formulations.

\subsubsection{Impact of LOE on Utilization Volume}

While measures of utilization volume are relatively straightforward for oral formulations (number tablets or capsules-what IMS Health calls standard units, or total milligrams of active pharmaceutical ingredient), for infused, injected, or otherwise physician-administered formulations, the measure of utilization volume is more ambiguous. IMS Health defines extended units as the number of tablets, capsules, milliliters, ounces, and so forth of a product shipped in each unit. This number is calculated by multiplying the number of units by the product size. Another volume measure is an "each," which represents "the number of single items (such as vials, syringes, bottles, or packet of pills) contained in a unit or shipping package and purchased by providers and pharmacies in a specific time period. An each is not a single pill or dosage of medicine (unless one package consists of a single dose), but may be the same as a unit if the unit does not subdivide into packages. Eaches are usually used to examine usage of injectable products. Eaches are most meaningful at the package level, since packages and their subunits may contain different quantities of strengths and volumes." ${ }^{4}$

4. From email correspondence between Berndt and Terry McMonagle at the IMS Institute for Healthcare Informatics, September 4, 2013, 11:15 a.m. 
Raw use and inflation-adjusted sales trends before and after LOE by formulation

\begin{tabular}{|c|c|c|c|c|c|c|c|}
\hline & \multicolumn{2}{|c|}{ Before LOE } & \multicolumn{2}{|c|}{ After LOE } & \multicolumn{3}{|c|}{ After - before } \\
\hline & $\begin{array}{c}\text { Monthly } \\
\text { average }\end{array}$ & $\begin{array}{l}\text { Std. } \\
\text { error }\end{array}$ & $\begin{array}{c}\text { Monthly } \\
\text { average }\end{array}$ & $\begin{array}{l}\text { Std. } \\
\text { error }\end{array}$ & Difference & $\begin{array}{l}\text { Std. } \\
\text { error }\end{array}$ & $\begin{array}{l}\text { Percent } \\
\text { change }\end{array}$ \\
\hline \multicolumn{8}{|l|}{ Oral $(n=15)$} \\
\hline Extended units & $1,508.4$ & 18.4 & 2,759 & 24.7 & $1,250.3$ & 30.8 & 82.9 \\
\hline Eaches & 121.5 & 1.7 & 158.5 & 1.6 & 37.03 & 2.29 & 30.5 \\
\hline Sales (2012 USD) & $1,356.1$ & 27.8 & $1,985.5$ & 30.3 & 629.42 & 41.1 & 46.4 \\
\hline \multicolumn{8}{|c|}{ Physician-administered infused/injected $(n=26)$} \\
\hline Extended units & 438.75 & 14.2 & 656.2 & 12.6 & 217.5 & 19.01 & 49.6 \\
\hline Eaches & 271.8 & 11.04 & 47.96 & 0.44 & 223.8 & 11.05 & 82.3 \\
\hline Sales (2012 USD) & $1,596.4$ & 20.9 & $2,506.6$ & 23.4 & 910.2 & 31.4 & 57.0 \\
\hline
\end{tabular}

Note $:$ Bold $=$ significant at the 1 percent level.

As an initial analysis of the impact of LOE on utilization volume, in table 9.8 we examine three measures of volume - average monthly extended units, average monthly eaches, and average monthly inflation-adjusted sales (2012 USD) separately for oral and injectable/infusible molforms, before LOE and generic entry, and after LOE and generic entry but aggregated over brand and generic versions for each molform. As seen in table 9.8, regardless of which volume measure used, average aggregate brand plus generic monthly utilization is greater post-LOE and generic entry than pre-LOE and generic entry for both oral and physician-administered infused/injected drugs.

However, a closer examination focused on the share of molforms within each aggregate category experiencing an increase reveals that these aggregate trends mask heterogeneity across drug formulations. To see this, we undertake a more detailed analysis of the impact of LOE on utilization volume involving estimation of various generalized least squares models with random effects in which the dependent variable is the log of volume, where volume is measured in extended units. Here again, the unit of observation is the molform month. In the specification of model 1 in table 9.9, the omitted reference case for the various indicator variables is pre-LOE time periods, an oral formulation, and a supportive therapeutic (e.g., an antinausea drug to mitigate side effects). We find that the estimated coefficient on the generic entry year indicator variable (taking on the value of one post-LOE and initial generic entry, else zero among oral formulated drugs) is positive and significant. Also consistent with the findings in table 9.8, although the estimated coefficient on the main effect injectable variable is negative (for the pre-LOE time periods), here we find that aggregate average monthly volume increases are large for injectable/infusible drugs following LOE, that is, the parameter estimate on the injectable-entry-year interaction variable 


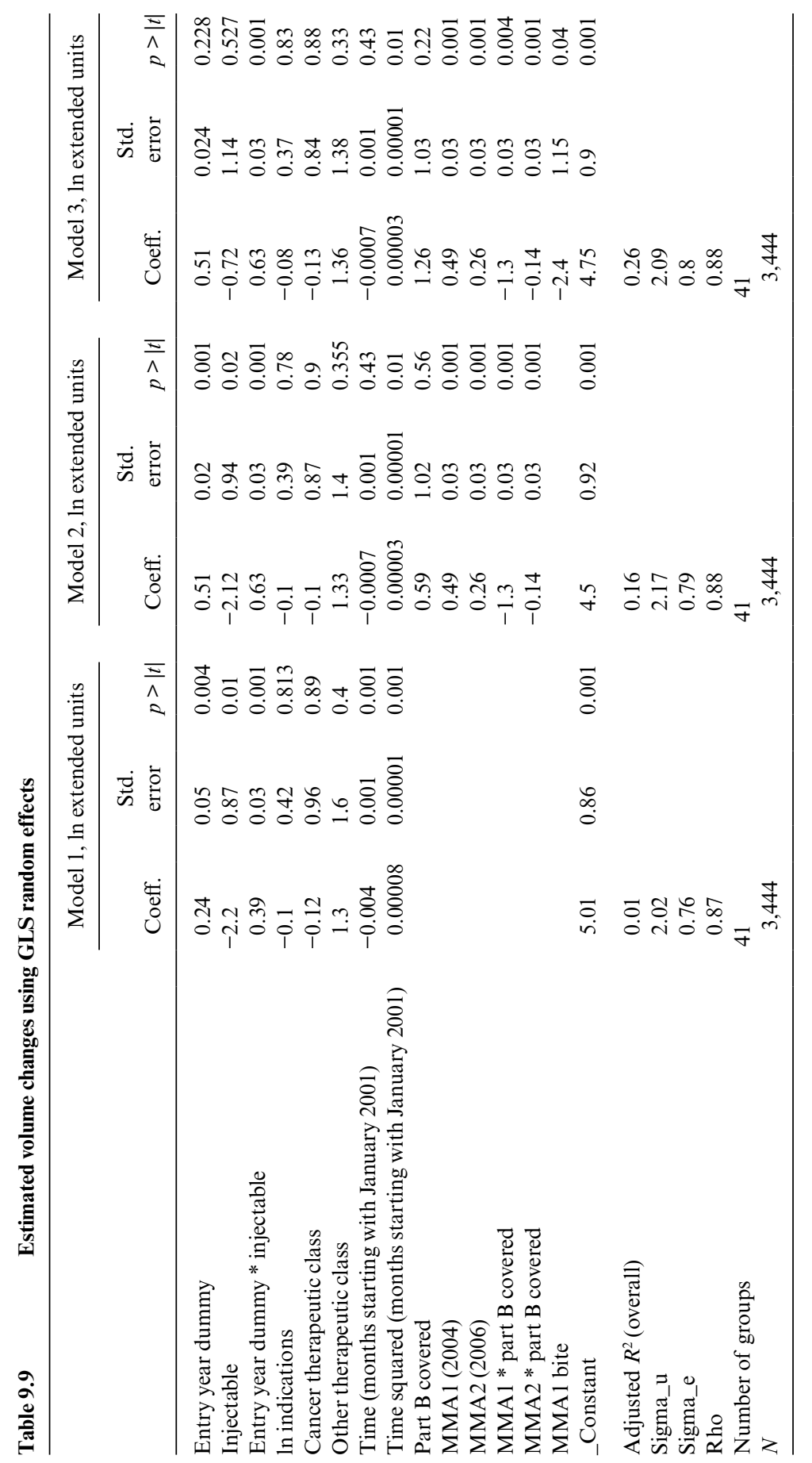


is positive and significant. While estimates on the therapeutic class indicator variables are statistically insignificant, coefficients on the continuous time variable (1 in January 2001, 2 in February 2001, etc.) and its square are small in magnitude, and negative and positive, respectively.

In model 2, the various MMA indicator variables and interactions with Part B variables are added to model 1. The omitted reference case for these variables is pre-MMA time periods for an oral drug covered by Medicare Part D. While estimates on the oral post-LOE (entry year dummy) and physician-administered post-LOE (entry year dummy * injectable interaction) variables in model 2 are robust in sign to their model 1 counterparts, in model 2 the magnitude of the use change is about twice that reported in model 1. In model 2 the estimates on MMA1 and MMA2 are both positive and significant, implying utilization of oral molforms experiencing LOE increased after these policy changes. However, we find estimates on the MMA-Part B interaction variables (interpreted as differences from the omitted pre-MMA-Part D variables) are both negative and significant, suggesting that the volume increases are concentrated among drugs covered under Part D, not Part B, and that post-MMA1 it is the Part B injectables whose volume decreases. Note that the absolute values of the estimated parameter on the post-MMA1 * Part B interaction value is larger than that of the post-MMA1 main effect variable, although this is not the case for the MMA2 interaction and main effect variable parameter estimates. Hence, it appears the reimbursement reduction for physician-administered Part B variables that took effect in MMA1 (between 2004:Q4 and 2005:Q1) is associated with a substantial decline in volume utilization.

Finally, in model 3, we added an additional variable "MMA1bite" to quantify the magnitude of (the absolute value of the) negative reimbursement shocks for some Part B-covered drugs but not others in 2004. Interestingly, except for the injectable and Part B main effects variables, estimated coefficients and their statistical significance for variables included in model 3 are remarkably robust to their values in model 2 . Molecules that experienced very large drops in reimbursement between 2004 and 2005 are found to have very large and statistically significant volume declines, holding all else constant.

\subsubsection{Predicting Shortage Reports as a Function of Manufacturer Counts, Preshortage Usage Trends}

Although none of our forty-one molforms experiencing LOE during 2001-2007 was ever reported in short supply during that time period, by 2008 or thereafter 18/41 (44 percent) were reported in short supply, with 67 percent of these (12/18) having experienced initial LOE prior to 2005.

This raises the intriguing issue of whether preshortage manufacturer counts and revenues, as well as time-invariant molform characteristics, can 
be used to predict subsequent shortage occurrences. We therefore estimated a cross-sectional logit model where the dependent variable takes on the value of one if the molform was eventually ever reported in short supply by the University of Utah, and zero if not. Since none of the molforms experiencing initial LOE 2001-2007 was in short supply during that time period, but instead experienced a shortage subsequently, we have latitude in choosing what is meant by the preshortage time period. A simple way to proceed to predict eventual shortage reports involves estimating a logit model with the forty-one molecules as observations, each observed for the three months of the last quarter in our data (2007:Q4), where the explanatory variables are similar to those specified in the count models (table 9.5) and use models (table 9.9). Results of the several such logit estimations are reported in table 9.10.

A number of the results are quite striking. In model 1, the omitted reference case is an oral molecule in the cancer supportive care therapeutic class. The large, positive, and significant parameter estimate on the injectable indicator variable implies that the probability of a shortage eventually occurring is $\exp (2.4)=11.02$ times greater for an injectable than an oral drug, and for a drug in a therapeutic class other than cancer or other therapeutic class it is only $\exp (-1.6)=0.20$ as likely to eventually be in short supply relative to a molecule in cancer supportive care. The greater the number of $\ln$ indications (FDA approved plus Medicare reimbursed), other things equal, the more likely an eventual shortage.

In model 2 we add ln mancount in 2007:Q4 and its square as regressors. With a positive estimate on the linear term and negative estimate on its squared value, $\ln$ mancount has an inverted U-shaped impact on the shortage probability.

In model 3, ln revenue in 2007:Q4 and its square are added as regressors to the model 2 specification. The positive estimates on the linear ln revenue variable and the negative estimates on its square imply that total brand plus generic $\ln$ revenues for a given molform has a diminishingly positive impact on shortage probability.

In both models 4 and 5, a Part B indicator variable and the MMA1bite variable measuring the absolute value of the Medicare reimbursement decline to providers are added. The estimated coefficient on the injectable indicator variable remains positive, but is approximately half its magnitude in models 1-3; the model 5 estimate of 1.2 implies the probability of an injectable drug eventually experiencing a shortage is $\exp (1.2)=3.29$ times greater than that of an oral specialty cancer drug, other things equal. An intriguing finding here is the positive, large, and statistically significant estimate on the MMA1bite variable, implying that the larger the Medicare reimbursement decline faced by providers when the MMA1 reforms were implemented between 2004:Q4 and 2005:Q1, the greater the probability that eventually in 2008 and beyond the drug would experience a shortage. 


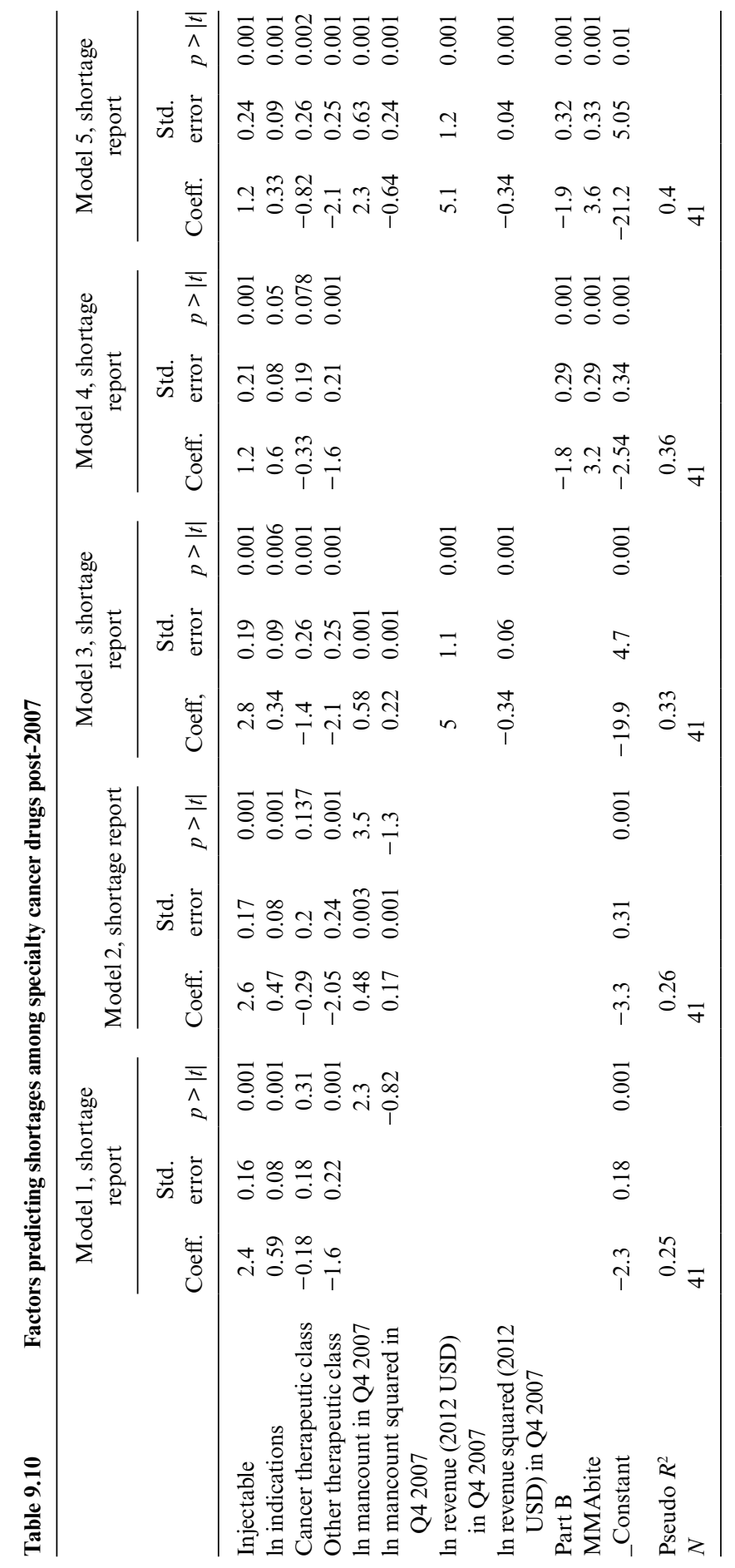




\subsubsection{Sensitivity Analyses}

To assess the robustness of our principal findings to alternative specifications and metrics, we undertook a number of investigations. For example, we examined use of revenue variables measured as the mean over varying molforms in the twenty-four and six months preceding ANDA entry (rather than twelve months), time-varying indication counts for each molform, orphan/priority review designation as a distinct measure of clinical quality, and the presence or absence of available therapeutic substitutes as determined by the FDA. We also pursued the construction and use of several market-specific measures of firm level costs, including parent and subsidiary relationships among firms based on table 9.4, and FDA regulatory cost compliance measures. We also estimated count models for entry in the first year, and two years following patent expiration. Our main findings are robust to each of these alternative definitions and/or specifications. They are available upon request from the lead author.

Finally, we recognize our measure of generic entry may violate our assumption of "simultaneous information" for a number of reasons. This includes the fact that the timing of generic entry may be endogenous to the number of firms entering into the market due to Paragraph IV filings and notifications (Panattoni 2011). We plan to examine this issue in future research.

\subsection{Discussion and Policy Implications}

This research has reported a number of findings regarding entry and pricing following LOE for specialty drugs that differ from patterns reported for nonspecialty oral solid tablets and capsules. First, as expected from our institutional review highlighting large fixed costs and economies of scale and scope for injectable/infusible drug manufacturing, we find preLOE production of cancer drugs to concentrate in several manufacturers, including Abbott, AstraZeneca, Bayer HealthCare, Bristol-Myers Oncology, Genzyme, GSK, Novartis, Pfizer, Roche, and Watson. Among generic manufacturers, APP, Bedford Laboratories, Teva Parenteral Me, and Teva Pharmaceuticals dominate the production of drugs undergoing initial LOE in our sample. We also observe the number of entrants into specialty drug LOEs to range between 1.66 and 4.99 manufacturers over all years, and what appears to be an upward trend in entry count in 2006 and 2007 compared to previous years. The limited number of manufacturers we observe entering the production of specialty drugs post-LOE is considerably smaller in magnitude than that reported in previous studies of entry into nonspecialty drugs. Nevertheless, these findings are consistent with that of the US Department of Health and Human Services, ASPE (2011), documenting that manufacturers of generic cancer drugs experienced a general increase 
in the quantity and mix of drugs they were producing in 2006 and thereafter, compared to 2000. A close inspection of entry trends into selected molforms also reveals several intriguing patterns. For example, among several specialty molecules, we observe exit by the branded manufacturer after LOE, as well as delayed and sequential ANDA entry into a given molecule undergoing LOE.

We also find evidence to suggest both entry and exit to be occurring among generic cancer drugs. For example, the average number of manufacturers of always generic cancer drugs available throughout the study period declines from 3.04 in 2001 to 2.3 in 2007. This winnowing of overall manufacturer counts per generic drug is consistent with other reports suggesting that merger and acquisition activities and outsourcing and/or discontinuations of previously offered generic drugs were common business practices during this period (US Department of Health and Human Services, ASPE 2011; FDA 2011). These results suggest generic manufacturers of cancer drugs may have been exiting from producing very old generic drugs and instead entering into segments experiencing initial LOE that offered potentially more profitable opportunities.

Economic theory suggests that the number of average entrants per new LOE is likely related to molecule-specific rationales and wider industry trends. We find evidence to support this theory; in each model presented the importance of molecule formulation and pre-LOE revenues appear to affect manufacturer entry counts. These former results are similar to those reported by Scott Morton (1999, 2000) and Iizuka (2009) and are likely related to the insurer coverage and reimbursement incentives operative in this specific drug market. The latter results are similar to those reported by Scott Morton (1999, 2000), Wiggins and Maness (2004), and Reiffen and Ward (2005) who also show that among their drug samples, pre-LOE sales measures explain a significant proportion of variation in the number of sellers in the post-LOE study period. Yet, we are well aware that when performing this test another potential endogeneity issue arises when aggregating across drugs reflecting unobserved differences between drugs that might affect both the prices and the number of entrants (Reiffen and Ward 2005). Finally, we do not find evidence to suggest the presence of tighter administered pricing policies for drugs clearly targeted by 2003 Medicare Modernization Act reforms (MMA1 in 2004) negatively affected the number of manufacturers entering into generic drug markets as they became available. In fact, among new opportunities we document robust and increasing entry after MMA1 implementation. This finding is tempered when we expressly examine the impact of negative price declines due to MMA reforms implemented in 2004 on entry patterns.

We also find that physician-administered drugs have higher inflationadjusted supplier prices compared to orally formulated drugs both before and after LOE. Furthermore, as expected, across all drug formulations we 
find inflation-adjusted supplier prices are negatively and statistically significantly related to the number of manufacturers producing them following LOE. Although the magnitudes of these price-number manufacturer effects are considerably larger here for physician-administered drugs, the qualitative effects reported here also mimic those found for oral generic and branded drugs following LOE (e.g., Aitken et al. 2013). Additional average price reductions continue to increase among drugs offered by five or more manufacturers (and the sign of the estimated parameter on the number of manufacturers squared is negative), particularly among physician-administered drug formulations and contrary to the literature examining nonspecialty drugs. This result is intriguing, since Gaynor and Vogt (2003), Mankiw and Whinston (2002), Berry and Reiss (2007), among others, suggest that anticipated profits in a variety of industries drops to zero after the entry of four or more firms. We also find evidence to suggest branded prices rise and generic prices fall in response to LOE and generic entry. This result is consistent with Frank and Salkever (1997), Ellison et al. (1997), Griliches and Cockburn (1994), and Aitken et al. (2013). We believe we are the first to report this finding in a specialty drug sample.

Our efforts provide contemporary estimates of volume utilization following the generic entry of specialty drugs. In all models, volume appears to increase substantially following generic entry, consistent with the usual assumptions regarding the negative relationship between prices and quantity demanded and empirical work among nonspecialty drugs undergoing LOE. However, these usage trends are much less robust among physician-administered formulations. Rather, the results of use models suggest MMA reimbursement reforms may have shifted utilization away from injectable Part B-reimbursed generic drugs after LOE, all else equal. This finding is also consistent with that reported by Jacobson et al. (2006, 2010), Jacobson, Earle, and Newhouse (2012), and Conti et al. (2012).

Regarding the welfare implications of these use results in this market, we fully acknowledge that they are complicated given the general aging of the population and increasing detection of cancer in combination with technological change supporting increased demand for combination products, all else equal (Scherer 1993; Cutler, Huckman, and Kolstad 2010). It is also unclear how to interpret these findings given the extent of simultaneous misuse, underuse, and overuse among cancer drugs (Conti et al. 2012) and the complicated agency relationship that rewards physicians and hospitals for the use of branded, highly reimbursed cancer drugs in treating cancer in the outpatient setting (Jacobson et al. 2006, 2010, 2013; Jacobson, Earle, and Newhouse 2012; Conti et al. 2012). As we discussed in the background section, this relationship among even oral specialty drugs is deepened by the lack of institutional incentives such as the tiered formularies adopted by payers to increase consumer price sensitivity regarding the use of generic drugs (Grabowski and Vernon 1992, 1996; Aitken, Berndt, and Cutler 2009). 
Lastly, finding mixed effects on utilization pattern, Caves, Whinston, and Hurwitz (1991), Berndt, Kyle, and Ling (2003), and Knittel and Huckfeldt (2012) suggest simultaneous declines in advertising and product reformulation introductions may act to mitigate the relationship between presumptive price declines and utilization increases associated with drugs following LOE. Yet, one advantage of our sample choice is that these changes have limited applicability to interpreting potential volume shifts among specialty drugs, since neither advertising nor new product formulations have been widely documented among physician-administered specialty drugs (Kornfield et al. 2013). Whether this trend is consistent across oral and injected/infused drugs among many other specialty therapeutic classes is an important direction for future research.

Nevertheless, we believe we can derive "second-best" welfare consequences from our price and utilization results. Recall there is a substantial literature examining the welfare effects of a monopolist implementing third-degree price discrimination relative to requiring a uniform monopoly price. We argue here that this literature may be important in understanding plausible welfare implications of our findings. Notably, among others, Varian $(1989,619-23)$ has shown that in the context of two groups of consumers and under quite general conditions, a necessary condition for welfare to increase under price discrimination relative to uniform pricing is that total volume increases under price discrimination. In the current context, readers can consider uniform pricing as that occurring when the product has patent protection, that is, the brand price prior to LOE. Following LOE, however, there are two groups of customers - the cost-conscious consumers who are attracted by low generic prices and the consumers who are more brand loyal; these two groups of customers pay different prices for the same bioequivalent product (Frank and Salkever 1997). Our pricing results suggest that supplier prices of generic drugs decline quite substantially after generic entry, while supplier prices of branded drugs rise after LOE; this finding is consistent with Frank and Salkever's work. Taken together, we suggest that our finding that post-LOE aggregate volumes of the molecule (brand plus generics) are greater than pre-LOE brand volumes supports a necessary condition for economic welfare gains among consumers of at least orally formulated specialty drugs to be satisfied, holding the above concerns in mind.

We conclude with several policy implications of our study. First, we note the number of manufacturers marketing specialty injectable/infusible drugs post-LOE in 2001-2007 is considerably smaller than has been observed for oral tablet and capsule formulations in previous studies. We have argued that one likely reason for this more limited entry post-LOE is that manufacturing specialty injectable/infusible formulations likely involves greater fixed and variable costs than for oral solid capsules and tablets. In this context, it is worth noting that provisions of the 2012 Generic Drug User Fee Amendments 
(GDUFA) not only assess one-time user fees for sponsors of ANDAs, but also entail annual payments by manufacturers to the FDA that vary by whether the manufacturing site is domestic or foreign, and whether the manufactured product is the active pharmaceutical ingredient or the final dosage form ("fill and finish"). This increase in manufacturing fixed costs can be expected to incentivize brand and generic drug firms to outsource their manufacturing to contract manufacturing organizations (CMOs), and since the annual user fee is site rather than product specific, it creates additional economies of scope that generate incentives for CMOs to increase the number of products manufactured at their site. To the extent that in addition CMOs are able to produce the same molform from different ANDA holders, the increased fixed costs and scale economies brought about by GDUFA may result in the further outsourcing of manufacturing to CMOs, and thereby reduce the number of distinct organizations manufacturing injectable/infusible drugs post-LOE. How these increased fixed costs in the presence of both increased economies of scope and scale will affect supplier prices is unclear, but worthy of further analysis.

Many of the injectable specialty drugs in our sample of forty-one molecules experiencing initial LOE in 2001-2007 are similar to currently patent-protected injectable biologics in the United States (Grabowski, Long, and Mortimer 2011). Thus, the patterns of entry, price, and use after LOE among specialty drugs we document may provide some insight into what might occur as patents of US biologics expire and they experience initial biosimilar entry. Yet we caution our reader: each of the drugs in our sample - branded and generic versions of specialty drugs - has been designated "fully interchangeable" by the FDA. Biosimilar entrants will likely be therapeutic substitutes to the branded innovator, but not necessarily "fully interchangeable" drugs. Thus, our estimates likely provide only an upper bound to the entry and price effects likely to occur as biologics go off patent in the United States.

Second, on drug shortages, 44 percent of our sample undergoing LOE between 2002 and July 2007 (eighteen molforms) were reported in short supply in 2008 or thereafter, and 67 percent of these molforms (twelve molforms) underwent generic entry prior to 2005. Our estimates are similar to that of IMS Institute for Healthcare Informatics' report (2011) suggesting the importance of the limited number of manufacturers of generic drugs previous to shortage reports. Among current shortages, the 2011 IMS Institute for Healthcare Informatics reported that 51 percent of the products with reported drug shortages had two or fewer suppliers, and two-thirds had three or fewer suppliers. Our results elaborate upon this finding, since the timing of our estimates suggests both the stock and flow of manufacturers into this market are constrained, that is, both the total number producing at any point in time, and the number of new entrants, are small. Our results also suggest shortage reports are concentrated among physician-administered 
injectable or infusible specialty drugs, having larger approved indication counts and larger revenues after LOE, holding all else equal. Intriguingly, we also find some suggestive evidence to support the contention that shortage reports concentrate among drugs particularly negatively affected by MMA reimbursement declines, holding molecule characteristics and other market features constant. This result supports Yurukoglu, Liebman, and Ridley (2012), although the effect we observe is likely via reduced physician demand, not reduced supply, given the incentives operative in "buy and bill" Medicare reimbursement policies. A thorough examination of the potential role of the MMA in inducing shortages is an important avenue for future empirical work. We also note in passing that while the probability of eventually being shorted is much greater for injectable than oral cancer specialty drugs in our sample, Stromberg (2014) reports strikingly similar temporal patterns of shortages among oral drugs, suggesting that time-varying factors common to injectable and oral drugs may be the root cause of shortages. Stromberg reports a statistically significant relationship between FDA regulatory activity (inspections and citations) and drug shortage rates over time.

Third, our review of the specialty drug market raises questions about researchers,' stakeholders,' and policymakers' definition of drug 'manufacturers" in that the increasingly important presence of time-varying and unobservable contract manufacturing practices complicate and may even undermine the definition of unique "manufacturers" entering this market, well beyond the usual concerns regarding ongoing merger and acquisition activities. Under current statute, NDA and ANDA sponsors are obligated to notify the FDA of plans to discontinue drug manufacturing as well as any changes in manufacturing responsibilities, including the outsourcing of drug production after initial approval. Furthermore, FDA sources say that it is common for a sponsor to need to qualify a new facility to manufacture their drug due to either the loss of the old facility or due to changing market demand, prompting the sponsor to acquire additional capacity. In these cases, NDA and ANDA sponsors often turn to contract manufacturers. However, data on the use of CMOs and their identity upon initial filings and subsequent changes is not publicly accessible through the web portal Drugs@FDA and is exempt from being released under the Freedom of Information Act (the FDA generally treats nonpublic business relationships as confidential commercial or financial information, exempting it from public disclosure). A proprietary data source, Truven's RedBook, maintains more updated information on which NDA and/or ANDA sponsors are actively offering a drug in the US market, but even this source does not identify contract-manufacturing arrangements. The identity and nature of base ingredient manufacturing (APIs) for many drugs, also collected by FDA from ANDA sponsors, are similarly shielded from public scrutiny.

We believe these increasingly important business practices have at least two implications for measuring the extent of generic competition. First, these 
arrangements make it challenging for regulators charged with monitoring competition in the generic and branded drug market to predict reliably what specialty drug supply of drugs will be following mergers, acquisitions, and/ or closures of NDA or ANDA sponsors and/or contract-manufacturing facilities supplying drugs to the US market. These relationships can make economic models of such activity and their potential competitive effects on supply and/or prices by agencies such as the Department of Justice or Federal Trade Commission inaccurate, particularly if overlapping supply is present before merger and acquisition activity between the two parties. Second, under these arrangements the public and their guardians are unable to quickly identify root causes of supply disruptions when supply or quality lapses occur. Indeed, one implication of our analysis is that the number of manufacturers with adequate capacity to manufacturer generic injectable drugs for the US market, including but not limited to those affected by shortages, is likely much smaller than previously documented. How best to formulate market-level solutions to supply lapses given extreme informational asymmetry regarding which manufacturers are actually producing these drugs or their base ingredients is uncharted territory.

\section{Appendix}

Table 9A.1

Molecules/forms in sample

\begin{tabular}{llr}
\hline \multicolumn{1}{c}{\begin{tabular}{l} 
Generic always \\
\multicolumn{1}{c}{$N=50$}
\end{tabular}} & \multicolumn{1}{c}{$\begin{array}{c}\text { Generic entry } \\
N=41\end{array}$} & $\begin{array}{c}\text { Entry } \\
\text { year }\end{array}$ \\
\hline Bleomycin IAG inject, mult. adm. reg. & Arsenic IAC inject, IV reg. & 2006 \\
Carmustine IAC inject, IV reg. & Busulfan OSR orals, sol., tab./cap. RE & 2003 \\
Chlorambucil OSR orals, sol., tab./cap. RE & Carboplatin IAC inject, IV reg. & 2004 \\
Cisplatin IAC inject, IV reg. & Cladribine IAG inject, mult. adm. reg. & 2004 \\
Cladribine IAC inject, IV reg. & Cladribine IAC inject, IV reg. & 2004 \\
Cytarabine IAG inject, mult. adm. reg. & Cyclophosphamide IAC inject, IV reg. & 2004 \\
Dacarbazine IAC inject, IV reg. & Cyclophosphamide OSR orals, sol., tab./cap. & 2004 \\
Daunorubicin IAC inject, IV reg. & Dexrazoxane IAK inject, infusion reg. & 2005 \\
Dolasetron IAC inject, IV reg. & Dexrazoxane IAC inject, IV reg. & 2005 \\
Doxorubicin IAC inject, IV reg. & Dimenhydrinate IAG inject, mult. adm. reg. & 2004 \\
Estramustine OSR orals, sol., tab./cap. re & Dimenhydrinate OSC orals, sol., chewable & 2002 \\
Etoposide IAC inject, IV reg. & Dimenhydrinate OSR orals, sol., tab./cap. RE & 2002 \\
Etoposide OSR orals, sol., tab./cap. RE & Dimenhydrinate scopolamine OSR orals, sol. & 2002 \\
Floxuridine IAC inject, IV reg. & Epirubicin IAC inject, IV reg. & 2006 \\
Fluorouracil DDC derm., cream & Fludarabine IAC inject, IV reg. & 2003 \\
Fluorouracil DDL derm., liquid/lotion & Idarubicin IAC inject, IV reg. & 2004 \\
Fluorouracil IAC inject, IV reg. & Ifosfamide IAC inject, IV reg. & 2004 \\
Fluorouracil TOZ other topicals & Ifosfamide mesna SAZ other systemics & 2004 \\
Flutamide OSR orals, sol., tab./cap. RE & Leuprolide IAA inject, IM reg. & 2004
\end{tabular}




\begin{tabular}{|c|c|c|}
\hline $\begin{array}{c}\text { Generic always } \\
\quad N=50\end{array}$ & $\begin{array}{c}\text { Generic entry } \\
N=41\end{array}$ & $\begin{array}{l}\text { Entry } \\
\text { year }\end{array}$ \\
\hline Fructose glucose phosphoric acid OLL OR & Leuprolide IAE inject, subcut. reg. & 2004 \\
\hline Fructose glucose phosphoric acid OSC OR & Leuprolide IAF inject, subcut. L. A. & 2004 \\
\hline Goserelin IAF inject, subcut L. A. & LeuprolidE SAZ other systemics & 2004 \\
\hline Hydroxyurea OSR orals, sol., tab./cap. RE & Leuprolide lidocaine SAZ other systemics & 2004 \\
\hline Leucovorin IAG inject, mult. adm. reg. & Mercaptopurine OSR orals, sol., tab./cap. RE & 2004 \\
\hline Leucovorin OSR orals, sol., tab./cap. RE & Mitoxantrone IAC inject, IV reg. & 2006 \\
\hline Lomustine OSR orals, sol., tab./cap. RE & Ondansetron IAC inject, IV reg. & 2006 \\
\hline Mechlorethamine IAC inject, IV reg. & Ondansetron IVR inject, IV pigback & 2007 \\
\hline Meclizine OSC orals, sol., chewable & Ondansetron OLL orals, liq., non-spec. L & 2007 \\
\hline Meclizine OSR orals, sol., tab./cap. RE & Ondansetron OLR orals, liq., ready-made & 2007 \\
\hline Megestrol OLR orals, liq., ready-made & Ondansetron OSO orals, sol., tab./cap. OT & 2007 \\
\hline Megestrol OSR orals, sol., tab./cap. RE & Ondansetron OSR orals, sol., tab./cap. RE & 2007 \\
\hline Mesna IAC inject, IV reg. & Pentostatin IAC inject, IV reg. & 2007 \\
\hline Mesna OSR orals, sol., tab./cap. RE & Scopolamine JWT insert/implant, transd. & 2003 \\
\hline Methotrexate IAG inject, mult. adm. reg. & Scopolamine OSR orals, sol., tab./cap. RE & 2003 \\
\hline Methotrexate OSR orals, sol., tab./cap. RE & Tamoxifen OSR orals, sol., tab./cap. RE & 2002 \\
\hline Methoxsalen IAX inject, other reg. & Tamoxifen OLL orals, liq., non-spec. L & 2002 \\
\hline Methoxsalen YAZ all others & Tretinoin OSR orals, sol., tab./cap. RE & 2007 \\
\hline Mitomycin IAC inject, IV reg. & Trimethobenzamide IAA inject, IM reg. & 2002 \\
\hline Mitotane OSR orals, sol., tab./cap. RE & Trimethobenzamide OSR orals, sol., tab./cap. & 2002 \\
\hline Paclitaxel IAC inject, IV reg. & Trimethobenzamide RRS rectals syst., supp. & 2002 \\
\hline Pegaspargase IAG inject, mult. adm. reg. & Vinorelbine IAC inject, IV reg. & 2003 \\
\hline \multicolumn{3}{|l|}{ Procarbazine OSR orals, sol., tab./cap. RE } \\
\hline \multicolumn{3}{|l|}{ Prochlorperazine IAG inject, mult. adm. RE } \\
\hline \multicolumn{3}{|l|}{ Prochlorperazine OSR orals, sol., tab./cap. } \\
\hline \multicolumn{3}{|l|}{ Prochlorperazine RRS rectals syst., supp. } \\
\hline \multicolumn{3}{|l|}{ Streptozocin IAC inject, IV reg. } \\
\hline \multicolumn{3}{|l|}{ Testolactone OSR orals, sol., tab./cap. RE } \\
\hline \multicolumn{3}{|l|}{ Thiotepa IAC inject, IV reg. } \\
\hline \multicolumn{3}{|l|}{ Vinblastine IAC inject, IV reg. } \\
\hline Vincristine IAC inject, IV reg. & & \\
\hline
\end{tabular}

Table 9A.2 Number of packages associated with each molform; bold indicates experiences generic entry in study period

\begin{tabular}{|c|c|c|c|c|c|}
\hline \multirow[b]{2}{*}{ Molform } & Molform label & \multicolumn{4}{|c|}{ Molform * packages count } \\
\hline & All molform & $\begin{array}{c}\text { Average } \\
1.3503012\end{array}$ & $\begin{array}{c}\text { SD } \\
0.60843\end{array}$ & $\begin{array}{c}\text { Min. } \\
1\end{array}$ & $\begin{array}{c}\operatorname{Max} . \\
10\end{array}$ \\
\hline 1 & Alemtuzumab IAC inject, IV reg. & 1 & 0 & & \\
\hline 2 & Alitretinoin DDG derm., gel & 1 & 0 & & \\
\hline 3 & Altretamine OSR orals, sol., tab./cap. RE & 1 & 0 & & \\
\hline 4 & Amifostine IAC inject, IV reg. & 1 & 0 & & \\
\hline 5 & Anastrozole OSR orals, sol., tab./cap. RE & 1 & 0 & & \\
\hline 6 & Aprepitant OSR orals, sol., tab./cap. RE & 1 & 0 & & \\
\hline
\end{tabular}




\begin{tabular}{|c|c|c|c|c|c|}
\hline \multirow[b]{2}{*}{ Molform } & Molform label & \multicolumn{4}{|c|}{ Molform * packages count } \\
\hline & All molform & $\begin{array}{l}\text { Average } \\
1.3503012\end{array}$ & $\begin{array}{c}\text { SD } \\
0.60843\end{array}$ & $\begin{array}{c}\text { Min. } \\
1\end{array}$ & $\begin{array}{c}\text { Max. } \\
10\end{array}$ \\
\hline 7 & Arsenic IAC inject, IV reg. & 1 & $\mathbf{0}$ & & \\
\hline 8 & Asparaginase IAG inject, mult. adm. reg. & 1 & 0 & & \\
\hline 9 & Azacitidine IAE inject, subcut. reg. & 1 & 0 & & \\
\hline 10 & Bevacizumab IAC inject, IV reg. & 1 & 0 & & \\
\hline 11 & Bexarotene DDG derm., gel & 1 & 0 & & \\
\hline 12 & Bexarotene OSR orals, sol., tab./cap. RE & 1 & 0 & & \\
\hline 13 & bicalutamide OSR orals, sol., tab./cap. RE & 1 & 0 & & \\
\hline 14 & Bleomycin IAG inject, mult. adm. reg. & 4.7 & 2 & 1 & 7 \\
\hline 15 & Bortezomib IAC inject, IV reg. & 1 & 0 & & \\
\hline 16 & Busulfan IAC inject, IV reg. & 1 & 0 & & \\
\hline 17 & Busulfan OSR orals, sol., tab./cap. RE & 1 & $\mathbf{0}$ & & \\
\hline 18 & Capecitabine OSR orals, sol., tab./cap. RE & 1.125 & 0.33 & 1 & 2 \\
\hline 19 & Carboplatin IAC inject, IV reg. & 4.3 & 2.81 & 1 & 10 \\
\hline 20 & Carmustine IAC inject, IV reg. & 1 & 0 & & \\
\hline 21 & Carmustine JJS insert/implant, sub. DE & 1 & 0 & & \\
\hline 22 & Cetuximab IAC inject, IV reg. & 1 & 0 & & \\
\hline 23 & Chlorambucil OSR orals, sol., tab./cap. RE & 1 & 0 & & \\
\hline 24 & Cisplatin IAC inject, IV reg. & 1.8 & 0.8 & 1 & 3 \\
\hline 25 & Cladribine IAC inject, IV reg. & 1.5 & 0.5 & 1 & 2 \\
\hline 26 & Cladribine IAG inject, mult. adm. reg. & 1 & $\mathbf{0}$ & & \\
\hline 27 & Clofarabine IAC inject, IV reg. & 1 & 0 & & \\
\hline 28 & Cyclizine OSR orals, sol., tab./cap. RE & 1 & 0 & & \\
\hline 29 & Cyclophosphamide IAC inject, IV reg. & 1.7 & 0.8 & 1 & 3 \\
\hline 30 & Cyclophosphamide OSR orals, sol., tab./cap. & 1.7 & 0.7 & 1 & 3 \\
\hline 31 & Cytarabine IAG inject, mult. adm. reg. & 1.5 & 0.5 & 1 & 2 \\
\hline 32 & Cytarabine IAZ inject, other L. A. & 1 & 0 & & \\
\hline 33 & Dacarbazine IAC inject, IV reg. & 2.2 & 1 & 1 & 4 \\
\hline 34 & Dactinomycin IAC inject, IV reg. & 1 & 0 & & \\
\hline 35 & Dasatinib OSR orals, sol., tab./cap. RE & 1 & 0 & & \\
\hline 36 & Daunorubicin IAC inject, IV reg. & 1.6 & 0.6 & 1 & 3 \\
\hline 37 & Decitabine IAC inject, IV reg. & 1 & 0 & & \\
\hline 38 & Denileukin diftitox IAK inject, infusion & 1 & 0 & & \\
\hline 39 & Dexrazoxane IAC inject, IV reg. & 1 & $\mathbf{0}$ & & \\
\hline 40 & Dexrazoxane IAK inject, infusion reg. & 1 & $\mathbf{0}$ & & \\
\hline 41 & Dimenhydrinate IAG inject, mult. adm. reg. & 1 & $\mathbf{0}$ & & \\
\hline 42 & Dimenhydrinate OSC orals, sol., chewable & 1 & $\mathbf{0}$ & & \\
\hline 43 & Dimenhydrinate OSR orals, sol., tab./cap. RE & 3.7 & 2 & 1 & 8 \\
\hline 44 & Dimenhydrinate scopolamine OSR orals, SO & 1 & $\mathbf{0}$ & & \\
\hline 45 & Docetaxel IAC inject, IV reg. & 1 & 0 & & \\
\hline 46 & Dolasetron IAC inject, IV reg. & 1 & 0 & & \\
\hline 47 & Dolasetron OSR orals, sol., tab./cap. RE & 1 & 0 & & \\
\hline 48 & Doxorubicin IAC inject, IV reg. & 2.4 & 1 & 1 & 4 \\
\hline 49 & Dronabinol OSR orals, sol., tab./cap. RE & 1 & 0 & & \\
\hline 50 & Electrolyte replacers OLL orals, liq., non & 1 & 0 & & \\
\hline 51 & Epirubicin IAC inject, IV reg. & 1.75 & 2 & 1 & 7 \\
\hline
\end{tabular}




\begin{tabular}{|c|c|c|c|c|c|}
\hline \multirow[b]{2}{*}{ Molform } & Molform label & \multicolumn{4}{|c|}{ Molform * packages count } \\
\hline & All molform & $\begin{array}{c}\text { Average } \\
1.3503012\end{array}$ & $\begin{array}{c}\text { SD } \\
0.60843\end{array}$ & $\begin{array}{c}\text { Min. } \\
1\end{array}$ & $\begin{array}{c}\text { Max. } \\
10\end{array}$ \\
\hline 52 & Erlotinib OSR orals, sol., tab./cap. RE & 1 & 0 & & \\
\hline 53 & Estramustine OSR orals, sol., tab./cap. RE & 1 & 0 & & \\
\hline 54 & Etoposide IAC inject, IV reg. & 2.2 & 1 & 1 & 4 \\
\hline 55 & Etoposide OSR orals, sol., tab./cap. RE & 1.2 & 0.33 & 1 & 2 \\
\hline 56 & Exemestane OSR orals, sol., tab./cap. RE & 1 & 0 & & \\
\hline 57 & Floxuridine IAC inject, IV reg. & 3 & 0 & 3 & 3 \\
\hline 58 & Fludarabine IAC inject, IV reg. & 1.9 & 1 & 1 & 5 \\
\hline 59 & Fluorouracil DDC derm., cream & 1.2 & 0.42 & 1 & 2 \\
\hline 60 & Fluorouracil DDL derm., liquid/lotion & 1.4 & 0.5 & 1 & 2 \\
\hline 61 & Fluorouracil IAC inject, IV reg. & 1.5 & 0.5 & 1 & 2 \\
\hline 62 & Fluorouracil TOZ other topicals & 1 & 0 & & \\
\hline 63 & Flutamide OSR orals, sol., tab./cap. RE & 2 & 1 & 1 & 4 \\
\hline 64 & Fosaprepitant OSR orals, sol., tab./cap. RE & 1 & 0 & & \\
\hline 65 & Fructose glucose phosphoric acid OLL OR & 1 & 0 & & \\
\hline 66 & Fructose glucose phosphoric acid OSC OR & 1 & 0 & & \\
\hline 67 & Fulvestrant IAA inject, IM reg. & 1 & 0 & & \\
\hline 68 & Gallium IAK inject, infusion reg. & 1 & 0 & & \\
\hline 69 & Gefitinib OSR orals, sol., tab./cap. RE & 1 & 0 & & \\
\hline 70 & Gemcitabine IAC inject, IV reg. & 1 & 0 & & \\
\hline 71 & Gemtuzumab ozogamicin IAC inject, IV reg. & 1 & 0 & & \\
\hline 72 & Ginger OSZ orals, sol., other & 1 & 0 & & \\
\hline 73 & Goserelin IAF inject, subcut. L.A. & 1 & 0 & & \\
\hline 74 & Granisetron IAC inject, IV reg. & 1 & 0 & & \\
\hline 75 & Granisetron OLL orals, liq., non-spec. L & 1 & 0 & & \\
\hline 76 & Granisetron OSR orals, sol., tab./cap. RE & 1 & 0 & & \\
\hline 77 & Histrelin SAZ other systemics & 1 & 0 & & \\
\hline 78 & Hydroxyurea OSR orals, sol., tab./cap. RE & 4.4 & 2.6 & 1 & 7 \\
\hline 79 & Ibritumomab tiuxetan SAZ other systemics & 1 & 0 & & \\
\hline 80 & Idarubicin IAC inject, IV reg. & 1.5 & 0.5 & 1 & 2 \\
\hline 81 & Ifosfamide IAC inject, IV reg. & 2.3 & 1 & 1 & 4 \\
\hline 82 & Ifosfamide mesna SAZ other systemics & 1.5 & 0.5 & 1 & 2 \\
\hline 83 & Imatinib OSR orals, sol., tab./cap. RE & 1 & 0 & & \\
\hline 84 & Irinotecan IAC inject, IV reg. & 1 & 0 & & \\
\hline 85 & Ixabepilone SAZ other systemics & 1 & 0 & & \\
\hline 86 & Lapatinib OSR orals, sol., tab./cap. RE & 1 & 0 & & \\
\hline 87 & Lenalidomide OSR orals, sol., tab./cap. RE & 1 & 0 & & \\
\hline 88 & Letrozole OSR orals, sol., tab./cap. RE & 1 & 0 & & \\
\hline 89 & Leucovorin IAG inject, mult. adm. reg. & 2.34 & 1 & 1 & 4 \\
\hline 90 & Leucovorin OSR orals, sol., tab./cap. RE & 1.9 & 0.8 & 1 & 3 \\
\hline 91 & Leuprolide IAA inject, IM reg. & 1.4 & 0.48 & 1 & 2 \\
\hline 92 & Leuprolide IAE inject, subcut. reg. & 1 & $\mathbf{0}$ & & \\
\hline 93 & Leuprolide IAF inject, subcut. L. A. & 1 & $\mathbf{0}$ & & \\
\hline 94 & Leuprolide SAZ other systemics & 2 & 0.8 & 1 & 3 \\
\hline 95 & Leuprolide lidocaine SAZ other systemics & 1 & $\mathbf{0}$ & & \\
\hline 96 & Lomustine OSR orals, sol., tab./cap. RE & 1 & 0 & & \\
\hline
\end{tabular}




\begin{tabular}{|c|c|c|c|c|c|}
\hline \multirow[b]{2}{*}{ Molform } & Molform label & \multicolumn{4}{|c|}{ Molform * packages count } \\
\hline & All molform & $\begin{array}{c}\text { Average } \\
1.3503012\end{array}$ & $\begin{array}{c}\text { SD } \\
0.60843\end{array}$ & $\underset{1}{\operatorname{Min} .}$ & $\begin{array}{c}\text { Max. } \\
10\end{array}$ \\
\hline 97 & Mechlorethamine IAC inject, IV reg. & 1 & 0 & & \\
\hline 98 & meclizine OSC orals, sol., chewable & 2 & 1 & 1 & 3 \\
\hline 99 & meclizine OSR orals, sol., tab./cap. RE & 4 & 2 & 1 & 10 \\
\hline 100 & medroxyprogesterone IAB inject, IM L. A. & 1 & 0 & & \\
\hline 101 & Megestrol OLR orals, liq., ready-made & 2.3 & 1.5 & 1 & 5 \\
\hline 102 & Megestrol OSR orals, sol., tab./cap. RE & 3.5 & 2.5 & 1 & 11 \\
\hline 103 & Melphalan IAC inject, IV reg. & 1 & 0 & & \\
\hline 104 & Melphalan OSR orals, sol., tab./cap. RE & 1 & 0 & & \\
\hline 105 & Mercaptopurine OSR orals, sol., tab./cap. RE & 2 & 1 & 1 & 3 \\
\hline 106 & Mesna IAC inject, IV reg. & 3.5 & 1.8 & 1 & 6 \\
\hline 107 & Mesna OSR orals, sol., tab./cap. RE & 1 & 0 & & \\
\hline 108 & Methotrexate IAG inject, mult. adm. reg. & 1.8 & 0.8 & 1 & 3 \\
\hline 109 & Methotrexate OSR orals, sol., tab./cap. RE & 3.3 & 2.7 & 1 & 9 \\
\hline 110 & Methoxsalen IAX inject, other reg. & 1 & 0 & & \\
\hline 111 & Methoxsalen YAZ all others & 1 & 0 & & \\
\hline 112 & Mitomycin IAC inject, IV reg. & 2.4 & 1 & 1 & 4 \\
\hline 113 & Mitotane OSR orals, sol., tab./cap. RE & 1 & 0 & & \\
\hline 114 & Mitoxantrone IAC inject, IV reg. & 2 & 2 & 1 & 6 \\
\hline 115 & Nabilone OSR orals, sol., tab./cap. RE & 1 & 0 & & \\
\hline 116 & Nelarabine IAC inject, IV reg. & 1 & 0 & & \\
\hline 117 & Nilotinib OSR orals, sol., tab./cap. RE & 1 & 0 & & \\
\hline 118 & Nilutamide OSR orals, sol., tab./cap. RE & 1 & 0 & & \\
\hline 119 & Ondansetron IAC inject, IV reg. & 2.7 & 2.6 & 1 & 10 \\
\hline 120 & Ondansetron IVR inject, IV pigback & 1.6 & 1 & 1 & 4 \\
\hline 121 & Ondansetron OLL orals, liq., non-spec. L & 1.5 & 0.5 & 1 & 2 \\
\hline 122 & Ondansetron OLR orals, liq., ready-made & 1 & $\mathbf{0}$ & & \\
\hline 123 & Ondansetron OSO orals, sol., tab./cap. OT & 2.3 & 1.8 & 1 & 6 \\
\hline 124 & Ondansetron OSR orals, sol., tab./cap. RE & 2.25 & 2.5 & 1 & 10 \\
\hline 125 & Oxaliplatin IAC inject, IV reg. & 1 & 0 & & \\
\hline 126 & Paclitaxel IAC inject, IV reg. & 4.5 & 2.6 & 1 & 9 \\
\hline 127 & Palifermin IAC inject, IV reg. & 1 & 0 & & \\
\hline 128 & Palonosetron IAC inject, IV reg. & 1 & 0 & & \\
\hline 129 & Panitumumab IAK inject, infusion reg. & 1 & 0 & & \\
\hline 130 & Pegaspargase IAG inject, mult. adm. reg. & 1 & 0 & & \\
\hline 131 & Pegylated liposomal doxorubicin IAC INJ & 1 & 0 & & \\
\hline 132 & pemetrexed IAC inject, IV reg. & 1 & 0 & & \\
\hline 133 & Pentostatin IAC inject, IV reg. & 1 & 0.4 & 1 & 2 \\
\hline 134 & Porfimer IAC inject, IV reg. & 1 & 0 & & \\
\hline 135 & Procarbazine OSR orals, sol., tab./cap. RE & 1 & 0 & & \\
\hline 136 & Prochlorperazine IAG inject, mult. adm. RE & 1.6 & 0.74 & 1 & 3 \\
\hline 137 & Prochlorperazine OSR orals, sol., tab./cap. & 2.8 & 1.5 & 1 & 6 \\
\hline 138 & Prochlorperazine RRS rectals syst., supp. & 2.9 & 2 & 1 & 6 \\
\hline 139 & Promethazine RRS rectals syst., supp. & 1 & 0 & & \\
\hline 140 & Rituximab IAK inject, infusion reg. & 1 & 0 & & \\
\hline 141 & Scopolamine JWT insert/implant, transd. & 1.4 & 0.5 & 1 & 2 \\
\hline
\end{tabular}




\begin{tabular}{|c|c|c|c|c|c|}
\hline \multirow[b]{2}{*}{ Molform } & Molform label & \multicolumn{4}{|c|}{ Molform * packages count } \\
\hline & All molform & $\begin{array}{c}\text { Average } \\
1.3503012\end{array}$ & $\begin{array}{c}\text { SD } \\
0.60843\end{array}$ & $\begin{array}{c}\text { Min. } \\
1\end{array}$ & $\begin{array}{c}\operatorname{Max} . \\
10\end{array}$ \\
\hline 142 & Scopolamine OSR orals, sol., tab./cap. RE & 1 & $\mathbf{0}$ & & \\
\hline 143 & Sorafenib OSR orals, sol., tab./cap. RE & 1 & 0 & & \\
\hline 144 & Streptozocin IAC inject, IV reg. & 1 & 0 & & \\
\hline 145 & Sunitinib OSR orals, sol., tab./cap. RE & 1 & 0 & & \\
\hline 146 & Tamoxifen OLL orals, liq., non-spec L & 1 & $\mathbf{0}$ & & \\
\hline 147 & Tamoxifen OSR orals, sol., tab./cap. RE & 2.8 & 1.7 & 1 & 6 \\
\hline 148 & Temozolomide OSR orals, sol., tab./cap. RE & 1 & 0 & & \\
\hline 149 & Temsirolimus SAZ other systemics & 1 & 0 & & \\
\hline 150 & Teniposide IAC inject, IV reg. & 1 & 0 & & \\
\hline 151 & Testolactone OSR orals, sol., tab./cap. RE & 1 & 0 & & \\
\hline 152 & Thiotepa IAC inject, IV reg. & 1.3 & 0.5 & 1 & 2 \\
\hline 153 & Topotecan IAC inject, IV reg. & 1 & 0 & & \\
\hline 154 & Toremifene OSR orals, sol., tab./cap. RE & 1 & 0 & & \\
\hline 155 & Tositumomab SAZ other systemics & 1.5 & 0.5 & 1 & 2 \\
\hline 156 & Trastuzumab IAC inject, IV reg. & 1 & 0 & & \\
\hline 157 & Tretinoin OSR orals, sol., tab./cap. RE & 1.1 & 0.4 & 1 & 2 \\
\hline 158 & Trimethobenzamide IAA inject, IM reg. & 1 & $\mathbf{0}$ & & \\
\hline 159 & Trimethobenzamide OSR orals, sol., tab./cap. & 1.4 & 0.5 & 1 & 2 \\
\hline 160 & Trimethobenzamide RRS rectals syst., supp. & 1.3 & 0.5 & 1 & 2 \\
\hline 161 & Triptorelin IAB inject, IM L. A. & 1 & 0 & & \\
\hline 162 & Valrubicin IAX inject, other reg. & 1 & 0 & & \\
\hline 163 & Vinblastine IAC inject, IV reg. & 1 & 0 & & \\
\hline 164 & Vincristine IAC inject, IV reg. & 1 & 0 & & \\
\hline 165 & Vinorelbine IAC inject, IV reg. & 3.8 & 2.3 & 1 & 8 \\
\hline 166 & Vorinostat OSR orals, sol., tab./cap. RE & 1 & 0 & & \\
\hline
\end{tabular}

Table 9A.3

Molecule by number of forms and clinical indications (on- and off-label)

\begin{tabular}{lccrc}
\hline Molform & $\begin{array}{c}\text { Molform } \\
\text { no. }\end{array}$ & $\begin{array}{c}\text { On } \\
\text { label }\end{array}$ & $\begin{array}{c}\text { Off } \\
\text { label }\end{array}$ & $\begin{array}{c}\text { Total } \\
\text { indications }\end{array}$ \\
\hline Arsenic IAC inject, IV reg. & 7 & 1 & 1 & 2 \\
Busulfan OSR orals, sol., tab./cap. RE & 16 & 3 & 2 & 5 \\
Carboplatin IAC inject, IV reg. & 19 & 2 & 17 & 19 \\
Cladribine IAC inject, mult. adm. reg. & 25 & 1 & 8 & 9 \\
Cladribine IAC inject, IV reg. & 26 & 1 & 8 & 9 \\
Cyclophosphamide IAC inject, IV reg. & 29 & 18 & 16 & 34 \\
Cyclophosphamide OSR orals, sol., tab./cap. & 30 & 18 & 16 & 34 \\
Dexrazoxane OAL omkct. omfisopm. reg. & 39 & 2 & 1 & 3 \\
Dexrazoxane IAC inject, IV reg. & 40 & 2 & 1 & 3 \\
Dimenhydrinate IAG inject, mult. adm. reg. & 41 & 1 & 1 & 2 \\
Dimenhydrinate OSC orals, sol., chewable & 42 & 1 & 1 & 2 \\
& & & & (continued)
\end{tabular}




\begin{tabular}{|c|c|c|c|c|}
\hline Molform & $\begin{array}{c}\text { Molform } \\
\text { no. }\end{array}$ & $\begin{array}{c}\text { On } \\
\text { label }\end{array}$ & $\begin{array}{c}\text { Off } \\
\text { label }\end{array}$ & $\begin{array}{c}\text { Total } \\
\text { indications }\end{array}$ \\
\hline Dimenhydrinate OSR orals, sol., tab./cap. RE & 43 & 1 & 1 & 2 \\
\hline Dimenhydrinate scopolamine OSR orals, SO & 44 & 1 & 1 & 2 \\
\hline Epirubicin IAC inject, IV reg. & 51 & 1 & 11 & 12 \\
\hline Fludarabine IAC inject, IV reg. & 58 & 1 & 8 & 9 \\
\hline Idarubicin IAC inject, IV reg. & 80 & 1 & 6 & 7 \\
\hline Ifosfamide IAC inject, IV reg. & 81 & 1 & 24 & 25 \\
\hline Ifosfamide mesna SAZ other systemics & 82 & 1 & 24 & 25 \\
\hline Leuprolide IAA inject, IM reg. & 91 & 4 & 7 & 11 \\
\hline Leuprolide IAE inject, subcut. reg. & 92 & 4 & 7 & 11 \\
\hline Leuprolide IAF inject, subcut. L. A. & 93 & 4 & 7 & 11 \\
\hline Leuprolide SAZ other systemics & 94 & 4 & 7 & 11 \\
\hline Mercaptopurine OSR orals, sol., tab./cap. RE & 105 & 1 & 5 & 6 \\
\hline Mitoxantrone IAC inject, IV reg. & 114 & 1 & 0 & 1 \\
\hline Ondansetron IAC inject, IV reg. & 119 & 4 & 1 & 5 \\
\hline Ondansetron IVR inject, IV pigback & 120 & 4 & 1 & 5 \\
\hline Ondansetron OLL orals, liq., no-spec. L & 121 & 4 & 1 & 5 \\
\hline Ondansetron OLR orals, liq., ready-made & 122 & 4 & 1 & 5 \\
\hline Ondansetron OSO orals, sol., tab./cap. OT & 123 & 4 & 1 & 5 \\
\hline Ondansetron OSR orals, sol., tab./cap. RE & 124 & 4 & 1 & 5 \\
\hline Pentostatin IAC inject, IV reg. & 133 & 1 & 3 & 4 \\
\hline Scopolamine JWT insert/implant, transd. & 141 & 2 & 1 & 3 \\
\hline Scopolamine OSR orals, sol., tab./cap. RE & 142 & 2 & 1 & 3 \\
\hline Tamoxifen OSR orals, sol., tab./cap. RE & 146 & 5 & 13 & 18 \\
\hline Tamoxifen OLL orals, liq. non-spec. L & 147 & 5 & 13 & 18 \\
\hline Tretinoin OSR orals, sol., tab./cap. RE & 157 & 5 & 8 & 13 \\
\hline Trimethobenzamide IAA inject, IM reg. & 158 & 1 & 0 & 1 \\
\hline Trimethobenzamide OSR orals, sol., tab./cap. & 159 & 1 & 0 & 1 \\
\hline Trimethobenzamide RRS rectals, syst., supp. & 160 & 1 & 0 & 1 \\
\hline Vinorelbine IAC inject, IV reg. & 165 & 1 & 11 & 12 \\
\hline
\end{tabular}

Table 9A.4 Molforms with shortages reported in years after study period

\begin{aligned} \hline Molform number & Molform \\ \hline 106 & Mesna IAC inject, IV reg. \\ 16 & Busulfan IAC inject, IV reg. \\ 111 & Methoxsalen YAZ all others \\ 152 & Thiotepa IAC inject, IV reg. \\ 24 & Cisplatin IAC inject, IV reg. \\ 54 & Etoposide IAC inject, IV reg. \\ 103 & Melphalan IAC inject, IV reg. \\ 112 & Mitomycin IAC inject, IV reg. \\ 4 & Amifostine IAC inject, IV reg. \\ 20 & Carmustine IAC inject, IV reg. \\ 80 & Idarubicin IAC inject, IV reg. \\ 84 & Irinotecan IAC inject, IV reg. \end{aligned}


(continued)

\begin{tabular}{|c|c|}
\hline Molform number & Molform \\
\hline 91 & Leuprolide IAA inject, IM reg. \\
\hline 126 & Paclitaxel IAC inject, IV reg. \\
\hline 19 & Carboplatin IAC inject, IV reg. \\
\hline 33 & Dacarbazine IAC inject, IV reg. \\
\hline 39 & Dexrazoxane IAC inject, IV reg. \\
\hline 48 & Doxorubicin IAC inject, IV reg. \\
\hline 57 & Floxuridine IAC inject, IV reg. \\
\hline 58 & Fludarabine IAC inject, IV reg. \\
\hline 74 & Granisetron IAC inject, IV reg. \\
\hline 119 & Ondansetron IAC inject, IV reg. \\
\hline 133 & Pentostatin IAC inject, IV reg. \\
\hline 163 & Vinblastine IAC inject, IV reg. \\
\hline 164 & Vincristine IAC inject, IV reg. \\
\hline 36 & Daunorubicin IAC inject, IV reg. \\
\hline 61 & Fluorouracil IAC inject, IV reg. \\
\hline 94 & Leuprolide SAZ other systemics \\
\hline 144 & Streptozocin IAC inject, IV reg. \\
\hline 32 & Cytarabine IAZ inject, other L. A. \\
\hline 92 & Leuprolide IAE inject, subcut. reg. \\
\hline 93 & Leuprolide IAF inject, subcut. L. A. \\
\hline 110 & Methoxsalen IAX inject, other reg. \\
\hline 14 & Bleomycin IAG inject, mult. adm. reg. \\
\hline 97 & Mechlorethamine IAC inject, IV reg. \\
\hline 120 & Ondansetron IVR inject, IV pigback \\
\hline 29 & Cyclophosphamide IAC inject, IV reg. \\
\hline 31 & Cytarabine IAG inject, mult. adm. reg. \\
\hline 55 & Etoposide OSR orals, sol., tab./cap. RE \\
\hline 89 & Leucovorin IAG inject, mult. adm. reg. \\
\hline 96 & Lomustine OSR orals, sol., tab./cap. RE \\
\hline 104 & Melphalan OSR orals, sol., tab./cap. RE \\
\hline 157 & Tretinoin OSR orals, sol., tab./cap. RE \\
\hline 40 & Dexrazoxane IAK inject, infusion reg. \\
\hline 108 & Methotrexate IAG inject, mult. adm. reg. \\
\hline 141 & Scopolamine JWT insert/implant, transd. \\
\hline 142 & Scopolamine OSR orals, sol., tab./cap. RE \\
\hline 18 & Capecitabine OSR orals, sol., tab./cap. RE \\
\hline 109 & Methotrexate OSR orals, sol., tab./cap. RE \\
\hline 30 & Cyclophosphamide OSR orals, sol., tab./cap. \\
\hline 38 & Denileukin diftitox IAK inject, infusion \\
\hline 105 & Mercaptopurine OSR orals, sol., tab./cap. RE \\
\hline 131 & Pegylated liposomal doxorubicin IAC INJ \\
\hline 136 & Prochlorperazine IAG inject, mult. adm. RE \\
\hline
\end{tabular}

\section{References}

Aitken, M. L., E. R. Berndt, B. Bosworth, I. M. Cockburn, R. G. Frank, M. Kleinrock, and B. T. Shapiro. 2013. "The Regulation of Prescription Drug Competition and Market Responses: Patterns in Prices and Sales Following Loss of Exclusivity." NBER Working Paper no. 19487, Cambridge, MA. 
Aitken, M. L., E. R. Berndt, and D. M. Cutler. 2009. "Prescription Drug Spending Trends in the United States: Looking beyond the Turning Point." Health Affairs 28 (1): w151-60.

Akscin, J., T. R. Barr, and E. L. Towle. 2007. "Key Practice Indicators in Office-Based Oncology Practices: 2007 Report on 2006 Data." Journal of Oncology Practice 3 (4): 200-203.

Barr, T. R., and E. L. Towle. 2011. "Oncology Practice Trends from the National Practice Benchmark, 2005 through 2010." Journal of Oncology Practice 7 (5): 286-90.

- 2012. "Oncology Practice Trends from the National Practice Benchmark." Journal of Oncology Practice 8 (5): 292-97.

Barr, T. R., E. L. Towle, and W. M. Jordan. 2008. "The 2007 National Practice Benchmark: Results of a National Survey of Oncology Practices." Journal of Oncology Practice 4 (4): 178-83.

Berndt, E. R., and M. Aitken. 2011. "Brand Loyalty, Generic Entry, and Price Competition in Pharmaceuticals in the Quarter Century after the 1984 Waxman-Hatch Legislation." International Journal of the Economics of Business 18 (2): 177-201.

Berndt, E. R., M. Kyle, and D. Ling. 2003. "The Long Shadow of Patent Expiration: Generic Entry and Rx-to-OTC Switches." In Scanner Data and Price Indexes, edited by Robert C. Feenstra and Matthew D. Shapiro. Chicago: University of Chicago Press.

Berndt, E. R., and J. P. Newhouse. 2013. "Pricing and Reimbursement in US Pharmaceutical Markets." In The Oxford Handbook of the Economics of the Biopharmaceutical Industry, edited by P. M. Danzon and S. Nicholson, 201-65. New York: Oxford University Press.

Berry S. 1992. "Estimation of a Model of Entry in the Airline Industry." Econometrica 60:889-917.

Berry, S., and P. Reiss. 2007. "Empirical Models of Entry and Market Structure.” In Handbook of Industrial Organization, vol. 3, edited by M. Armstrong and R. H. Porter, 1845-86. Amsterdam: North Holland Elsevier.

Bresnahan, T. F., and P. Reiss. 1988. "Do Entry Conditions Vary across Markets?" Brookings Papers on Economic Activity: Microeconomics 1987 (3): 833-81.

1991. "Entry and Competition in Concentrated Markets." Journal of Political Economy 99:977-1009.

Caves, R., M. D. Whinston, and M. Hurwitz. 1991. "Patent Expiration, Entry and Competition in the US Pharmaceutical Industry." Working Paper, Brookings Papers on Economic Activity: Microeconomics https://www.brookings.edu/wp -content/uploads/1991/01/1991_bpeamicro_caves.pdf.

Clemens, J., and J. D. Gottlieb. 2013. "Bargaining in the Shadow of a Giant: Medicare's Influence on Private Payment Systems." NBER Working Paper no. 19503, Cambridge, MA.

Conti, R. M. 2014. "Who Makes this Drug?" The Cancer Letter, January 3. http:// www.cancerletter.com/articles/20140103.

Conti, R. M., A. C. Bernstein, V. M. Villaflor, R. L. Schilsky, M. B. Rosenthal, and P. B. Bach. 2013. "Prevalence of Off-Label Use and Spending in 2010 among Patent-Protected Chemotherapies in a Population-Based Cohort of Medical Oncologists." Journal of Clinical Oncology 31 (9): 1134-39.

Conti, R. M., M. B. Rosenthal, B. Polite, P. B. Bach, and Y-C. T. Shih. 2012. "Infused Chemotherapy Use Following Patent Expiration among Individuals Aged 65 and Older." American Journal of Managed Care 18 (5): e173-78.

Cutler, D. M., R. Huckman, and J. T. Kolstad. 2010. "Input Constraints and the Efficiency of Entry: Lessons from Cardiac Surgery." American Economic Journal: Economic Policy 2 (1): 51-76. 
Drug Channels. 2014. "EXCLUSIVE: 340B is Taking over the Hospital MarketWith a 25\% Share." February 25. http://www.drugchannels.net/2014/02/exclusive -340b-is-taking-over-hospital.html.

Duggan, M., and F. Scott Morton. 2010. "The Effect of the Medicare Drug Benefit on Pharmaceutical Prices and Utilization." American Economic Review 100 (1): 590-607.

Ellison, S. F., I. M. Cockburn, Z. Griliches, and J. A. Hausman. 1997. "Characteristics of Demand for Pharmaceutical Products: An Examination of Four Cephalosporins." Rand Journal of Economics 28 (3): 1-36.

EMD Serono. 2013. EMD Serono Specialty Digest ${ }^{\mathrm{TM}}$, 9 th ed. Managed Care Strategies for Specialty Pharmaceuticals. http://specialtydigest.emdserono.com/Digest .aspx.

Frank, R. G. 2001. "Prescription Drug Prices: Why Some Pay More Than Others Do." Health Affairs 20 (2): 325-30.

Frank, R. G., and D. S. Salkever. 1992. "Pricing, Patent Loss and the Market for Pharmaceuticals." Southern Economic Journal 59:165-79.

_. 1997. "Generic Entry and the Pricing of Pharmaceuticals." Journal of Economics and Management Strategy 6 (1): 75-90.

Gatesman, M., and T. Smith. 2011. "The Shortage of Essential Chemotherapy Drugs in the United States." New England Journal of Medicine 365 (18): 1653-55.

Gaynor, M. S., and W. Vogt. 2003. "Competition among Hospitals." Rand Journal of Economics 34 (4): 764-85.

Goldberg, P. 2013. "Drug Shortages Reach All-Time High-Ben Venue Exit Will Make Problem Worse." The Cancer Letter, October 11. http://www.cancerletter .com/articles/20131011.

Grabowski, H., G. Long, and R. Mortimer. 2011. "Implementation of the Biosimilar Pathway: Economic and Policy Issues." Seton Hall Law Review 41 (2): 511-57.

Grabowski, H., and J. Vernon. 1992. "Brand Loyalty, Entry and Price Competition in Pharmaceuticals after the 1984 Drug Act." Journal of Law and Economics 35:331-50.

- 1996. "Longer Patents for Increased Generic Competition in the US: The Waxman-Hatch Act after One Decade." PharmacoEconomics 10 (suppl. 2): 110-23.

Griliches, Z., and I. M. Cockburn. 1994. "Generics and New Goods in Pharmaceutical Price Indexes." American Economic Review 84 (5): 1213-32.

Iizuka T. 2009. "Generic Entry in a Regulated Pharmaceutical Market.” Japanese Economic Review 60 (1): 63-81.

IMS Institute for Healthcare Informatics. 2011. "Drug Shortages: A Closer Look at Products, Suppliers, and Volume Volatility." http://www.imshealth.com/deployed files/ims/Global/Content/Insights/IMS $\% 20$ Institute $\% 20$ for $\% 20$ Healthcare $\% 20$ Informatics/Static\%20Files/IIHI_Drug_Shortage_Media_ExecSumm.pdf.

Jacobson, M., A. Alpert, and F. Duarte. 2012. "Prescription Drug Shortages: Reconsidering the Role of Medicare Payment Policies." Health Affairs blog, May 29. http://healthaffairs.org/blog/2012/05/29/prescription-drug-shortages-reconsidering -the-role-of-medicare-payment-policies/.

Jacobson, M., C. Earle, and J. Newhouse. 2012. "Geographic Variation in Physicians' Responses to a Reimbursement Change." New England Journal of Medicine 365 (22): 2049-52.

Jacobson, M., C. Earle, M. Price, and J. Newhouse. 2010. "How Medicare's Payment Cuts For Cancer Chemotherapy Drugs Changed Patterns of Treatment." Health Affairs 29 (7): 1391-99.

Jacobson, M., T. C. Chang, J. P. Newhouse, and C. C. Earle. 2013. "Physician Agency and Competition: Evidence from a Major Change to Medicare Chemotherapy 
Reimbursement Policy.”NBER Working Paper no. 19247, Cambridge, MA. http:// users.nber.org/ changt/Jacobsonetal_20130624.pdf.

Jacobson, M., A. J. O’Malley, C. C. Earle, J. Pakes, P. Gaccione, and J. P. Newhouse. 2006. "Does Reimbursement Influence Chemotherapy Treatment for Cancer Patients?" Health Affairs 25 (2): 437-43.

Knittel, P. J., and C. R. Huckfeldt. 2012. "Pharmaceutical Use following Generic Entry: Paying Less and Buying Less." MIT Working Paper. http://web.mit.edu/ knittel/www/papers/hk_latest.pdf.

Kornfield, R., J. Donohue, E. R. Berndt, and G. C. Alexander. 2013. "Promotion of Prescription Drugs to Consumers and Providers, 2001-2010." PLoS One 8 (3): e55504.

Kyle, M. K. 2006. "The Role of Firm Characteristics in Pharmaceutical Product Launches." RAND Journal of Economics 37 (3): 602-18.

Macher, J., and J. Nickerson. 2006. "Pharmaceutical Manufacturing Research Project, Final Benchmarking Report." Report, Georgetown University and Washington University in St. Louis. http://apps.olin.wustl.edu/faculty/nickerson/results/ PMRPFinalReportSept2006.pdf.

Malin, J. L., J. C. Weeks, A. L. Potosky, M. C. Hornbrook, and N. L. Keating. 2013. "Medical Oncologists' Perceptions of Financial Incentives in Cancer Care." Journal of Clinical Oncology 31 (5): 530-35.

Mankiw, N. G., and M. D. Whinston. 2002. "Free Entry and Social Inefficiency." Rand Journal of Economics 17:48-58.

MedPAC. 2006. "Report to the Congress: Effects of Medicare Payment Changes on Oncology Services." Washington, DC, Medicare Payment Advisory Commission. http://www.medpac.gov/publications/congressional_reports/Jan06_Oncology _mandated_report.pdf.

Neumann, P. J. 2005. Using Cost-Effectiveness Analysis to Improve Health Care. Oxford: Oxford University Press.

Panattoni, L. 2011. "The Effect of Paragraph IV Decisions and Generic Entry before Patent Expiration on Brand Pharmaceutical Firms." Journal of Health Economics 30 (1): $126-45$.

PAREXEL. 2013. PAREXEL Biopharmaceutical R\&D Statistical Sourcebook 2012 2013. http://www.barnettinternational.com/EducationalServices_Publication.aspx $? \mathrm{p}=10145 \& \mathrm{id}=115966$.

Pharmacy Benefit Management Institute (PBMI). 2014. "2014 Specialty Drug Benefit." http://reports.pbmi.com/report.php?id=5.

Pindyck, R. S., and D. L. Rubinfeld. 2013. Microeconomics, 8th ed. New York: Prentice-Hall.

Reiffen, D., and M. R. Ward. 2005. "Generic Drug Industry Dynamics." Review of Economics and Statistics 87 (1): 37-49.

Scherer, F. M. 1993. "Pricing, Profits, and Technological Progress in the Pharmaceutical Industry." Journal of Economic Perspectives 7 (3): 97-115.

Scott Morton, F. M. 1999. "Entry Decisions in the Generic Pharmaceutical Industry." RAND Journal of Economics 30 (3): 421-40.

.2000. "Barriers to Entry, Brand Advertising, and Generic Entry in the US Pharmaceutical Industry.” International Journal of Industrial Organization 18: $1085-104$.

Stromberg, C. 2014. "Drug Shortages, Pricing, and Regulatory Authority." Unpublished Manuscript, Washington, DC:, Bates-White LLC. February.

Tirole, J. 1988. The Theory of Industrial Organization. Cambridge, MA: MIT Press.

Towle, E. L., and T. R. Barr. 2009. "2009 National Practice Benchmark: Report on 2008 Data.” Journal of Oncology Practice 5 (5): 223-27. 
2010. "National Practice Benchmark: 2010 Report on 2009 Data." Journal of Oncology Practice 6 (5): 228-31. Erratum in Journal of Oncology Practice 2011 7 (2): 134.

Towle, E. L., T. R. Barr, and J. L. Senese. 2012. "National Oncology Practice Benchmark, 2012 Report on 2011 Data." Journal of Oncology Practice 8 (6): 51s-70s.

US Department of Health and Human Services, Assistant Secretary of Planning and Evaluation (ASPE). 2011. Economic Analysis of the Causes of Drug Shortages. Issue Brief, October. http://aspe.hhs.gov/sp/reports/2011/DrugShortages/ib.shtm. , Centers for Medicare and Medicaid Services (CMS). 2014. Medicare Fee for Service Part B Drugs Reimbursement Fee Schedules 2005-2013. http://www.cms .gov/Medicare/Medicare-Fee-for-Service-Part-B-Drugs/McrPartBDrugAvgSales Price/2013ASPFiles.html.

. 2010. Drug Manufacturers' Noncompliance with Average Manufacturer Price Reporting Requirements. http://oig.hhs.gov/oei/reports/oei-03-09-00060.pdf.

- 2011. "Medicare Payments for Newly Available Generic Drugs." Report no. OEI-03-09-00510. https://oig.hhs.gov/oei/reports/oei-03-09-00510.pdf.

US Food and Drug Administration (FDA). 2011. Pathway for Global Drug Safety and Quality. http://www.fda.gov/AboutFDA/CentersOffices/OfficeofGlobal RegulatoryOperationsandPolicy/GlobalProductPathway/default.htm.

- 2013. Strategic Plan for Preventing and Mitigating Drug Shortages. http:// www.fda.gov/downloads/Drugs/DrugSafety/DrugShortages/UCM372566.pdf.

US Government Accountability Office (GAO). 2004. "Medicare Chemotherapy Payments: New Drug and Administration Fees Are Closer to Providers' Costs." Report no. GAO-05-142R. http://www.gao.gov/new.items/d05142r.pdf.

. 2011. "Manufacturer Discounts in the 340B Program Offer Benefits, but Federal Oversight Needs Improvement." Report no. GAO-11-836. http://www .gao.gov/new.items/d11836.pdf.

_. 2013. "Information on Highest-Expenditure Part B Drugs." Report no. GAO-13-739T. http://www.gao.gov/products/GAO-13-739T.

Varian, H. R. 1989. "Price Discrimination.” In Handbook of Industrial Organization, vol. 1, edited by R. L. Schmalensee and R. Willig, 597-654. Amsterdam: North Holland Elsevier.

Wiggins, S. N., and R. Maness. 2004. "Price Competition in Pharmaceuticals: The Case of Anti-Infectives." Economic Inquiry 42 (2): 247-63.

Wilson, D. 2012. "Deepening Drug Shortages." Health Affairs (Millwood) 31 (2): 263-66.

Woodcock, J., and M. Wosinska. 2013. "Economic and Technological Drivers of Sterile Injectable Drug Shortages.” Clinical Pharmacology \& Therapeutics 93 (2): 170-76. http://www.nature.com/clpt/journal/v93/n2/full/clpt2012220a.html.

Yurukoglu, A., E. Liebman, and D. B. Ridley. 2012. "The Role of Government Reimbursement in Drug Shortages." NBER Working Paper no. 17987, Cambridge, MA. 